\title{
Proposed Alternatives for a DOE-Wide Occupational Radiation Exposure Information System
}

\author{
B. L. Murphy \\ D. W. Murphy \\ J. J. Fix \\ J. M. Selby, PNL Project Manager \\ E. J. Vallario, DOE Project Manager
}

February 1984

Prepared for the U.S. Department of Energy under Contract DE-AC06-76RLO 1830

Pacific Northwest Laboratory Operated for the U.S. Department of Energy by Battelle Memorial Institute 


\title{
DISCLAIMER
}

This report was prepared as an account of work sponsored by an agency of the United States Government. Neither the United States Government nor any agency thereof, nor any of their employees, makes any warranty, express or implied, or assumes any legal liability or responsibility for the accuracy, completeness, or usefulness of any information, apparatus, product, or process disclosed, or represents that its use would not infringe privately owned rights. Reference herein to any specific commercial product, process, or service by trade name, trademark, manufacturer, or otherwise, does not necessarily constitute or imply its endorsement, recommendation, or favoring by the United States Government or any agency thereof. The views and opinions of authors expressed herein do not necessarily state or reflect those of the United States Government or any agency thereof.

\author{
PACIFIC NORTHWEST LABORATORY \\ operated by \\ BATTELLE \\ for the \\ UNITED STATES DEPARTMENT OF ENERGY \\ under Contract DE-AC06-76RLO 1830
}

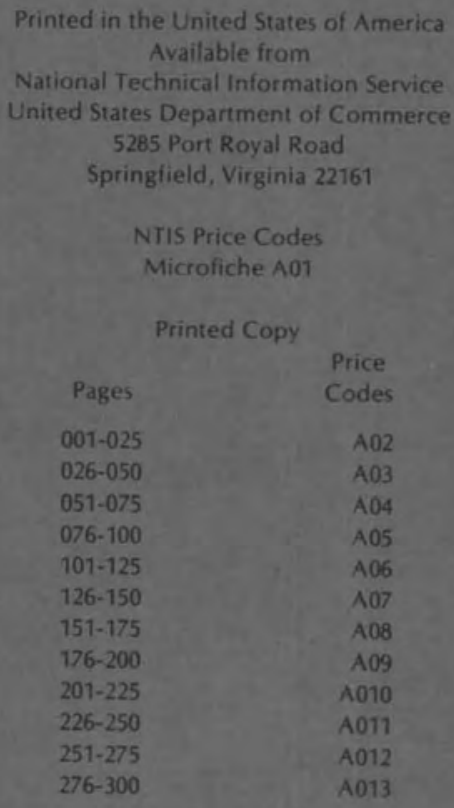


PROPOSED ALTERNATIVES FOR A DOE-WIDE OCCUPATIONAL RADIATION EXPOSURE INFORMATION SYSTEM

B. L. Murphy $(a)$

J. J. Fix

J. M. Selby, PNL Project Manager

E. J. Vallario, DOE Project Manager

February 1984

Prepared for the U.S. Department of Energy under Contract DE-AC06-76RLO 1830

Pacific Northwest Laboratory

Richland, Washington 99352

(a) Currently at Reynolds Electrical \& Engineering Company Las Vegas, Nevada 


\title{
FOREWORD
}

The Department of Energy (DOE) needs to provide timely responses to requests for information from other federal agencies, Congress, and the public. This need has become more important since public attention to radiation exposures associated with government operations (past and present) has increased. Therefore, DOE initiated a study to determine the adequacy of the present DOE system for reporting occupational radiation exposures, to identify necessary short-term improvements, and to propose feasible alternatives for an improved system. Studies concerning the recording of individual occupational exposure histories at DOE sites have also been proposed. Two reports al ready completed as part of the present study are

- PNL-3450, Overview of DOE Radiation Exposure Information Reporting System (REIRS)

- PNL-3538, Current Personnel Dosimetry Practices at DOE Facilities.

Pertinent information contained in these reports is repeated as necessary in this third report, to provide an understanding of the alternatives identified.

\author{
E. J. Vallario \\ Group Leader \\ Health Physics Programs \\ Office of Nuclear Safety \\ U.S. Department of Energy
}




\section{EXECUTIVE SUMMARY}

The Radiation Exposure Information Reporting System (REIRS) was initiated by the Atomic Energy Commission (AEC) in 1968. With the exception of modifications to reflect changing radiation protection policy and standards, REIRS has not undergone any substantial change in character since its inception. While the system has provided a general overview of radiation exposures associated with $A E C / E R D A(a) / D O E$ operations and has satisfied the original intent for a central information system, the need for more detailed information has become evident. The records currently in REIRS contain summary data from the sites and additional information on terminated employees only. These records are not sufficient for DOE to respond to most inquiries from congressional committees, to prepare reports for other federal agencies, or to assess the impact of proposed standards and policies on its operation. Efforts to obta in this type of information are time consuming and costly. Additionally, communication problems exist between the sites and the reporting system, and the methods used to generate summary dose information result in inconsistent determinations.

Because of these problems, DOE initiated a study to 1) review the present recording practices at contractor sites, 2) review REIRS, and 3) recommend changes in REIRS or develop an alternative system. The first two tasks have been completed and this document is concerned with the final part of the study. Additional studies concerning DOE site-specific recording practices have been proposed.

The alternatives addressed for a radiation exposure information system are:

1. no change in current system

2. clarification of DOE Order for current system

3. increased summary information from sites

4. centralized annual individual dose (exposure) system

5. annual dose summary and locator files.

(a) Energy Research and Development Administration. 
For each alternative, the site input requirements, the attributes and limitations, and the costs and benefits are discussed in reference to the alternative's capability of meeting the requirements of an adequate system. In conjunction with this study, an Ad Hoc Committee on Occupation Exposure Registry Upgrade was formed by DOE Headquarters to review the study findings and make recommendations concerning alternative record systems. A majority of the DOE Ad Hoc Committee has concurred with a recommendation to implement Alternative 5, the annual dose summary and locator files (ADSLF).

The ADSLF system would require that sites annually provide two sets of files to a records library. The first set would contain actual dose information for monitored personnel; however, no personal identifications would be maintained as part of the files. The second set, called locator files, would be a listing of all employees and of badged visitors who were at the site during the calendar year. The ADSLF system would be responsible for the generation of both individual site and DOE-wide summary data. The cost and manpower required to implement this system would be low because the information and data already exist at most sites. The implementation of the system would result in a considerable improvement in the availability of data and information. Funding would be required to implement the system at the ADSLF records library, and the annual operating costs at the records library would be slightly higher than the cost of maintaining the present records system.

The acceptance of the ADSLF alternative as the DOE-wide radiation exposure system would give DOE added capability and flexability in responding to requests for information and would reduce the impact on the sites of special survey requests. The development of a DOE and DOE contractor employee locator file would enable the rapid identification of personnel in the DOE system. For example, the file would facilitate responses to requests for dose information on an individual who had worked or was working at more than one DOE site. With many sites presently reviewing and upgrading their historical records, the addition to the locator file of available information on past employees would be encouraged and would increase the effectiveness of the system. Applicable information that is presently maintained in the terminated-employee exposure files would be moved into the employee locator file so that this 
historical information would be maintained. Finally, the recommended ADSLF alternative would be flexible enough to accept changes in radiation protection standards and policies. 
๑ 


\section{ACKNOWLEDGMENTS}

The authors wish to express their appreciation to a 11 those individuals who provided information and recommendations for this report. Bill Millet of the Safety System Development Center (SSDF) in Idaho Falls had numerous suggestions and provided an initial appraisal of the existing repository. A DOE and DOE contractor Ad Hoc Committee on Occupational Exposure Registry Upgrade reviewed and recommended changes in the report. In addition, comments and recommendations were received from 26 respondents to the U.S. DOE memorandum dated July 1, 1982, "Request for Review of Final Draft Report, Proposed Alternatives for a DOE-Wide Occupational Radiation Exposure Information System." Ed Vallario and Joe Fitzgerald of the DOE Office of Nuclear Safety were instrumental in determining the need for the study and in arranging and maintaining funding. Marianna Cross, PNL, provided the necessary production and coordination support. 


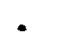


AD HOC COMMITTEE ON OCCUPATIONAL

EXPOSURE REGISTRY UPGRADE

Jack M. Selby (Chairman)

Pacific Northwest Laboratory

P.0. Box 999

Richland, WA 99352

Bob E. Casey

Brookhaven National Laboratory

Upton, NY 11973

Jack Elliott

Lawrence Livermore National Laboratory

7000 East Avenue

Livermore, CA 94550

Joe Fitzgerald

U.S. Department of Energy

Office of Nuclear Safety

Washington, DC 20545

Jack J. Fix

Pacific Northwest Laboratory

P.0. Box 999

Richland, WA 99352

Pat Humphrey

MS F692

Los Alamos National Laboratory

Los Alamos, NM 87545

Jim Lawrence

MS P229

Los Alamos National Laboratory

Los Alamos, NM 87545

\author{
Andrew Maluish (Consultant) \\ Research Services, Inc. \\ 65 Bralan Ct. \\ Gaithersburg, MD 20877 \\ Michael Marelli \\ U.S. Department of Energy \\ Dosimetry Branch \\ Health Physics Division \\ Nevada Operations Office \\ P. 0. Box 14100 \\ 2753 S. Highland \\ Las Vegas, NV 98114 \\ Jack D. McLendon \\ Union Carbide \\ Y-12 Plant \\ Oak Ridge, TN 37830 \\ Bryce Rich \\ EG\&G/Idaho, Inc. \\ 1955 Fremont Avenue \\ P.0. Box 1625 \\ Idaho Falls, ID 83415 \\ Robert E. Yoder \\ Rockwell International \\ P. 0. Box 464 \\ Golden, C0 80401
}




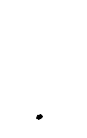

$x$

$\star$ 
CONTENTS

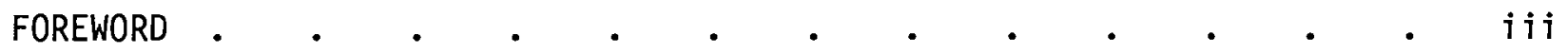

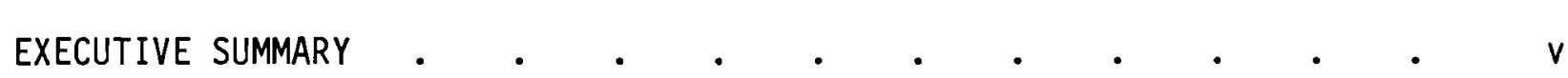

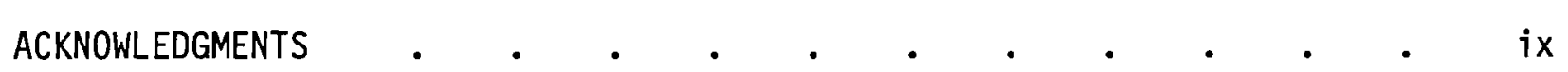

AD HOC COMMITTEE ON OCCUPATIONAL EXPOSURE REGISTRY UPGRADE.$\quad \cdot \quad \cdot \quad x i$

INTRODUCTION

CRITERIA FOR OCCUPATIONAL RADIATION EXPOSURE INFORMATION SYSTEM • $\quad$ • 4

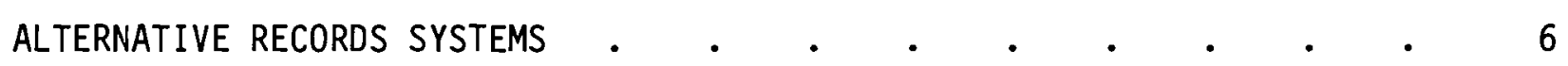

ALTERNATIVE 1 - NO CHANGE IN CURRENT SYSTEM • • • • • • 6

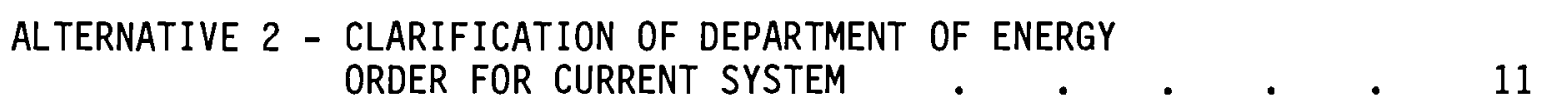

ALTERNATIVE 3 - INCREASED SUMMARY INFORMATION FROM SITES • • 13

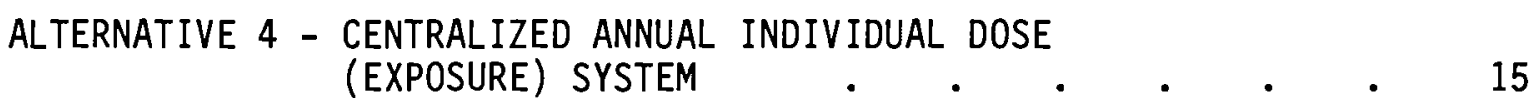

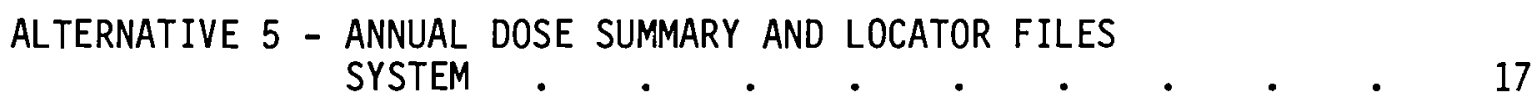

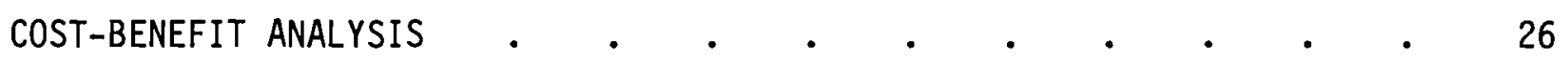

COST-BENEFIT TECHNIQUES FOR ANALYSIS OF ALTERNATIVES • • • • 26

RESULTS OF COST-BENEFIT ANALYSIS

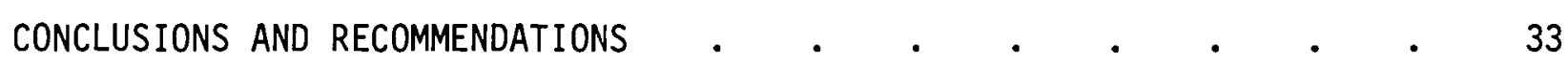

REFERENCES •

APPENDIX A - EXAMPLE OF SUMMARY TABLES • . . . . . . . . . . A.1

APPENDIX B - COST ANALYSIS . . . . . . . . . . . . . B. B

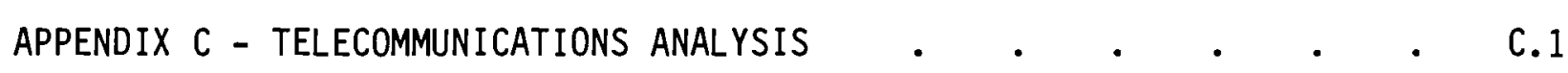

APPENDIX D - FIELD REVIEW COMMENTS AND RESPONSES • • • • • • $\quad$ • D.1 


\section{TABLES}

1 Distribution of Whole-Body Ionizing Radiation Exposures for Department of Energy (DOE) and DOE Contractor Employees, $1965-1980$

2 Distribution of Annual Whole-Body Exposures for Department of Energy (DOE) and DOE Contractor Employees and Visitors by Facility Type, 1980

3 Frequency Distributions Developed Directly from Records at 43 Department of Energy Contractor Sites . . . . . 14

4 Initial Reporting Criteria for Internal Exposure--Phase I . . 23

5 Benefits Matrix . . . . . . . . . . . 27

6 Estimated Costs for Each Alternative . . . . . . 28

7 Five-Year Life-Cycle Cost Analysis . . . . . . . . 29

8 Cost-Benefit Ratio Analysis . . . . . . . . . 30

9 Summarized Assessment of Alternatives . . . . . . 34 


\section{INTRODUCTION}

This report proposes changes to improve the Department of Energy's (DOE) centralized data base maintained at EG\&G, Idaho, and presently known as the Radiation Exposure Information Reporting System (REIRS). This system maintains statistical summaries of occupational radiation exposures for DOE activities in addition to former Atomic Energy Commission (AEC) and Energy Research and Development Administration (ERDA) activities. Occupational radiation exposure histories for individual workers are maintained by each DOE and DOE contractor site. The records maintained at the DOE and DOE contractor sites are an integral part of the overall DOE records system; however, recommendations concerning site recording practices are not addressed in this report.

The need for a central information and records system on occupational radiation exposures, with established procedures for submission and reporting, was formally recognized in 1966. At that time, two counterpart bills (H.R. 16920 and S. 3722) were submitted to Congress on behalf of the AEC to financially support a Federal-State-Employer Radiation Recordkeeping System for all radiation workers. The impetus behind this proposal was the lack of comprehensive and consistent exposure records for radiation workers that, as a minimum, would permit the compilation of accurate exposure histories. Adequate exposure histories, although essential for several reasons, were needed primarily for purposes of workmen's compensation and medical followups. Also, the need was recognized to identify worker populations who, by virtue of their radiation exposure, may be of importance for prospective epidemiological studies.

Extensive hearings on radiation recordkeeping were held before the Joint Committee on Atomic Energy in 1966; however, resolution of the bills was not achieved. At the request of the Commission, an AEC staff paper concerning the establishment of a central radiation records repository for AEC and AEC contractor employees was written in 1967. The paper recommended that uniform requirements be prescribed for the collection and reporting of occupational exposure data. These recommendations coincided with the Congressional initiatives requiring consistent, complete, and available record information that 
would allow epidemiological studies. These requirements were incorporated into AEC Manual Chapter (MC) 0525, "Radiation Exposure Information Report System" (REIRS), in 1968 and were implemented on March 12, 1969, via an Immediate Action Directive from the General Manager, AEC. The requirements of AEC Manual Chapter 0525 were incorporated into the Energy Research and Development Administration's (ERDA's) Manual Chapter 0525, and subsequently into the Department of Energy's (DOE's) Order 5484.1, (3) which covers reporting requirements for environmental, safety, and health protection information. With the exception of modifications to reflect changing radiation protection policy and standards, REIRS has undergone no substantial changes in character since its inception.

Although REIRS has provided a general overview of radiation exposures associated with AEC/ERDA/DOE operations and has satisfied the original intent for a central information system, the need for more detailed information has become evident. Experience has demonstrated that, in addition to annual reports, DOE requires information to respond to the following types of requests:

1. urgent requests
a. congressional comittee inquiries
b. radiation injury compensation claims, medical case history investigations, Freedom of Information or similar requests for summary data
c. accidents/incidents

2. special surveys
a. trend analyses
b. impact assessments, e.g., for proposed standards or policies
c. reports to other agencies, e.g., the Nuclear Regulatory Commission, Environmental Protection Agency, Department of Labor, and Health and Human Services (Bureau of Radio- logical Health)
d. field office/contractor safety performance

3. annual DOE occupational exposure report. 
The present records at REIRS contain summary data from the sites and additional information on terminated employees only. This information is not sufficient for DOE to respond to many of the inquiries detailed above. Requests of an urgent nature are currently responded to, and special surveys are currently conducted, by direct contact with the field offices and contractors possessing the individual worker records. Providing expedient responses on an ad hoc basis has thus been resource intensive and has disrupted staff at DOE Headquarters and field offices.

The current reporting system also has little application to either the field office or the contractor beyond the compilation of the DOE annual reports. A different type of records system could permit the sites to:

1. determine where occupational exposure histories of current and past employees are located (exposure histories are now located on an ad hoc basis through information given by the employee)

2. compare exposure data by craft and by contractor to monitor performance in keeping exposures as low as is reasonably achievable (ALARA).

Recognizing the information needs outlined above, DOE initiated a study to review REIRS and to recommend changes. Two previous reports resulting from that study provided an overview of REIRS ${ }^{(1)}$ and of the current personnel dosimetry and records practices at contractor sites. (2) As part of the current portion of the study, 13 criteria were identified that would make an exposure information reporting system most useful to DOE and its field offices and contractors. The information contained in the earlier reports, in addition to that provided by the Ad Hoc Committee on Occupational Exposure Registry Upgrade formed by DOE Headquarters, was then utilized to propose alternative record systems.

The criteria for a useful records system are presented in the next section of this report. The following section is a discussion of the five alternatives, including for each one the site input requirements, and the alternative's attributes and limitations. A cost-benefit analysis of the alternatives is then presented, followed by conclusions and recommendations. 


\section{CRITERIA FOR OCCUPATIONAL RADIATION EXPOSURE INFORMATION SYSTEM}

An effective and useful information system should provide the data necessary to meet the needs and requirements of DOE Headquarters, DOE field offices, and DOE contractors. After reviewing both the current system and the ability of DOE Headquarters to respond to requests and/or surveys, it was determined that an effective information system must be programed to meet the following criteria:

1. Urgent Request Response: The system should give DOE the capability to respond to information requests from Congress, other government agencies, and the public (via the Freedom of Information Act).

2. Special Surveys: The system should allow for special trend analyses, such as assessing the impact of proposed changes in radiation protection standards, and identifying specific exposures (beta, gamma, neutron, extremity, etc.).

3. Reports: The system should be able to retrieve and compile information for the annual DOE radiation exposure report and other special reports that may be requested.

4. Consistent Data Input: DOE orders, which identify the data that are to be reported to the information system, must be clear and concise enough to be uniformly interpreted.

5. Employee Identification: The system should be capable of identifying present DOE and DOE contractor employees. For each individual, the system should include information on all DOE and DOE contractor locations at which the individual has worked and the period of employment at each location.

6. Visitor Identification: The system should be capable of identifying visitors who were monitored for potential radiation exposure at any DOE or DOE contractor site. 
7. Accurate Surmary Data: The system should provide for the review and verification of summary data and should include an editing capability. The system should also ensure that the data are summarized using consistent arithmetic procedures.

8. Nonduplication of Data: The system should minimize the amount of data maintained by both the information system and the individual sites.

9. Privacy Act: The system should ensure the privacy of the individual and the confidentiality of individual exposure data.

10. Usefulness: The DOE and DOE contractors should have confidence in the usefulness and accuracy of the system and use it to obtain information for improving their own monitoring and safety programs.

11. Implementation Costs: Funds to cover the costs of implementing the system, as well as annual maintenance and operating costs, should be obtainable under the present fiscal restraints. However, the selection of a system should not be affected by the possible lack of funds or the potential need for supplemental funds.

12. Implementation: The time required to implement the system should be minimal.

13. Site Impact: The impact on DOE field offices and contractor sites should be minimal. The implementation costs of the system should not place a significant financial burden on the sites, and annual operating costs should not increase significantly.

The first ten criteria are primarily related to informational needs, and the last three are related to the timing and financial aspects of implementing and operating the system. The following section provides descriptions of the al ternative systems and discusses each system's ability to meet the above criteria. 


\section{ALTERNATIVE RECORDS SYSTEMS}

Five alternatives were considered for upgrading the DOE occupational radiation exposure information system. The alternatives were developed using the existing REIRS system, and some new approaches. Regardless of the system selected by DOE, the data provided by the DOE field office and contractor sites would be maintained in a designated records library.

The alternatives considered for the modification of REIRS were:

1. no change in current system

2. clarification of DOE order for current system

3. increased summary information from sites

4. centralized annual individual dose (exposure) system

5. annual dose summary and locator files system.

The information and exposure data submitted to the records system, regardless of the alternative selected, would be for radiation workers. For the purpose of this report, a radiation worker is defined as: any person who works with ionizing radiation or radioactive material and who may receive in the normal course of employment an exposure equal to or greater than ten percent (10\%) of the radiation protection standard outlined in DOE Order 5480.1, Chapter XI. (4)

Due to the difficulties associated with reconstructing historical data, the proposed alternatives were developed and evaluated from a prospective standpoint only. As time and funding permit, the addition of available historical information to the system should be considered. Each alternative's input requirements, attributes, and 1 imitations are discussed in detail in the following subsections.

\section{ALTERNATIVE 1 - NO CHANGE IN CURRENT SYSTEM}

Input

Department of Energy contractors would continue submitting to REIRS the exposure information currently required by DOE Order 5484.1. (3) The information submitted would include 1) an annual summary of whole-body ionizing radiation exposure, 2) an internal exposure summary, and 3) a termination 
occupational exposure report. Using information from the contractors' reports, REIRS would continue to provide DOE Headquarters with a quarterly update of terminated employees by name, social security number, and exposure, and annual summary data for use in the DOE annual reports.

Annual Summary of Whole-Body Ionizing Radiation Exposure

The number of individuals who received a whole-body exposure in one of 18 dose-equivalent intervals ranging from "less than measurable" to "greater than 12 rem" would be provided annually by each DOE contractor and DOE field office. These same dose intervals would be used to subdivide radiation doses by facility classes. This information would be used to prepare summaries such as those shown in Tables 1 and 2, which were taken from a DOE annual exposure report. (5)

\section{Internal Exposure Summary}

A report of internal body deposition of radioactive materials would be required for: 1) any uptake of radioactive material occurring during the reporting year that independently, or when added to a current burden, is estimated to result in a dose commitment to the critical organ in excess of $50 \%$ of the pertinent annual dose equivalent standards detailed in DOE Order 5480.1 , Chapter $X I^{(4)}$; or 2) any previously unreported uptake of radioactive material that is determined to be reportable according to the above criteria by reason of the most recent dose-equivalent estimate.

\section{Termination Occupational Exposure Report}

The submission of a termination form would be required for each monitored visitor and for each monitored employee who for any reason terminated employment with DOE or a DOE contractor. Information on the form would include the employer's code and the employee's date of hire, date of birth, termination date, and internal and external dose equivalent (including the time interval for which the exposures were monitored).

$\underline{\text { Attributes }}$

A historical summary (Table 1) of radiation exposures since the inception of REIRS in 1968 would continue to be available. This data has been used in 
TABLE 1. Distribution of Whole-Body Ionizing Radiation Exposures for Department of Energy (DOE) and DOE Contractor Employees, 1965-1980(5)

Dose Equivalent Ranges (rem)

\begin{tabular}{|c|c|c|c|c|c|c|c|c|c|c|c|c|c|c|c|}
\hline \multirow[b]{3}{*}{ Year } & \multicolumn{14}{|c|}{ Dose Equivalent Ranges (rem) } & \multirow{3}{*}{$\begin{array}{c}\text { Total } \\
\text { Monitored }\end{array}$} \\
\hline & \multicolumn{2}{|c|}{$0-1(a)$} & \multirow[b]{2}{*}{$1-2$} & \multirow[b]{2}{*}{$2-3$} & \multirow[b]{2}{*}{$3-4$} & \multirow[b]{2}{*}{$4-5$} & \multirow[b]{2}{*}{$5-6$} & \multirow[b]{2}{*}{$6-7$} & \multirow[b]{2}{*}{$7-8$} & \multirow[b]{2}{*}{$8-9$} & \multirow[b]{2}{*}{$9-10$} & \multirow[b]{2}{*}{$10-11$} & \multirow[b]{2}{*}{$11-12$} & \multirow[b]{2}{*}{$>12$} & \\
\hline & <Meas. & Meas.-1 & & & & & & & & & & & & & \\
\hline 1965 & \multicolumn{2}{|c|}{128,360} & 4,158 & 1,704 & 515 & 294 & 70 & 32 & 26 & 25 & 22 & 6 & 2 & & 135,214 \\
\hline 1966 & \multicolumn{2}{|c|}{131,522} & 3,706 & 1,630 & 593 & 313 & 88 & 47 & 24 & 6 & 2 & & & 1 & 137,932 \\
\hline 1967 & \multicolumn{2}{|c|}{102,510} & 3,472 & 1,572 & 555 & 168 & 35 & 29 & 23 & 17 & 4 & 1 & & & 108,386 \\
\hline 1968 & \multicolumn{2}{|c|}{103,206} & 2,799 & 1,408 & 425 & 144 & 3 & 1 & & & & & & & 107,986 \\
\hline 1969 & \multicolumn{2}{|c|}{98,625} & 2,554 & 1,313 & 335 & 86 & 4 & & & . & & 1 & & & 102,918 \\
\hline 1970 & \multicolumn{2}{|c|}{92,185} & 2,698 & 1,329 & 279 & 158 & 5 & 4 & 2 & & 1 & & & & 96,661 \\
\hline 1977 & \multicolumn{2}{|c|}{90,640} & 2,380 & 688 & 275 & 118 & 8 & 3 & & & & 1 & & 2 & 94,315 \\
\hline 1972 & \multicolumn{2}{|c|}{86,077} & 2,130 & 929 & 219 & 95 & 8 & 2 & & & & & & & 89,460 \\
\hline 1973 & \multicolumn{2}{|c|}{89,071} & 1,944 & 727 & 172 & 60 & 2 & 1 & & & & & & & 91,977 \\
\hline 1974 & 43,184 & 32,500 & 1,667 & 688 & 149 & 40 & 4 & & & & & & & & 78,232 \\
\hline 1975 & 43,310 & 42,141 & 1,846 & 753 & 232 & 142 & & & & 1 & & & & & 88,425 \\
\hline 1976 & 40,083 & 47,886 & 1,679 & 475 & 70 & 6 & 1 & & & & & & & & 90,200 \\
\hline 1977 & 43,017 & 49,948 & 1,579 & 545 & 103 & 23 & & & 1 & 2 & & & & 2 & 95,220 \\
\hline 1978 & 44,898 & 55,296 & 1,323 & 439 & 53 & 11 & & & & & & & - & & 102,020 \\
\hline $1979(b)$ & 50,003 & 53,235 & 1,286 & 416 & 33 & 10 & 1 & & & & 0 & & & 2 & 104,986 \\
\hline 1980 & 45,054 & 38,895 & 1,113 & 387 & 16 & & & & & & & & & & 85,465 \\
\hline
\end{tabular}

(a) Separation of data prior to 1974 is unavailable.

(b)The 1979 data differs slightly from those listed in the original 1979 report because of an error in the dose-equivalent calculation by a contractor. 

TABLE 2. Distribution of Annual Whole-Body Exposures for Department of Energy (DOE)
and DOE Contractor Employees and Visitors by Facility Type, 1980

Dose Equivalent Ranges (rem)

\begin{tabular}{|c|c|c|c|c|c|c|c|c|c|c|c|c|c|c|c|c|c|c|c|c|}
\hline \multirow[b]{2}{*}{$\begin{array}{l}\text { Facility } \\
\text { Type }\end{array}$} & \multirow[b]{2}{*}{$\begin{array}{c}\text { Total } \\
\text { Monliored }\end{array}$} & \multicolumn{18}{|c|}{ Dose Equivalent Ranges (rem) } & \multirow[b]{2}{*}{$\begin{array}{c}\text { Total } \\
\text { Person-Rem }\end{array}$} \\
\hline & & $\begin{array}{c}< \\
\text { Meas. }\end{array}$ & $\begin{array}{c}\text { Meas.- } \\
0.10\end{array}$ & $\begin{array}{l}0.10 \\
0.25 \\
\end{array}$ & $\begin{array}{l}0.25- \\
0.50 \\
\end{array}$ & $\begin{array}{l}0.50 \\
0.75 \\
\end{array}$ & $\begin{array}{l}0.75- \\
1.00 \\
\end{array}$ & $1-2$ & $2-3$ & $3-4$ & $4-5$ & $5-6$ & $6-7$ & $7-8$ & $8-9$ & 9-10 & $10-11$ & $11-12$ & $\geq 12$ & \\
\hline Reactor & 6,921 & 2.654 & 2,569 & 699 & 449 & 171 & $\pi$ & 165 & 135 & 2 & & & & & & & & & & 1,185 \\
\hline $\begin{array}{l}\text { Fuel } \\
\text { Fabrication }\end{array}$ & 2,102 & 734 & 793 & 266 & 143 & 57 & 43 & 55 & 11 & & & & & & & & & & & 323 \\
\hline $\begin{array}{l}\text { Fuel } \\
\text { Processing }\end{array}$ & 3,147 & $\pi 8$ & 1,041 & 356 & 329 & 199 & 116 & 237 & 91 & & & & & & & & & & & 1,047 \\
\hline $\begin{array}{l}\text { Uran. } \\
\text { Enrichment }\end{array}$ & 1,871 & 535 & 861 & 364 & 87 & 19 & 4 & 1 & & & & & & & & & & & & 156 \\
\hline Weapon F\&T & 15,904 & 8,659 & 5,967 & 629 & 315 & 143 & 82 & 93 & 14 & 2 & & & & & & & & & & 869 \\
\hline Gen. Research & 36,110 & 22,933 & 10,749 & 1,225 & 558 & 296 & 155 & 163 & 24 & 7 & & & & & & & & & & 1,611 \\
\hline Accelerator & 5,315 & 3,347 & 1,244 & 360 & 159 & $\pi$ & 45 & 70 & 11 & 2 & & & & & & & & & & 412 \\
\hline Other & 12,037 & 3,670 & 5,670 & 982 & 631 & 282 & 169 & 329 & 101 & 3 & & & & & & & & & & 1,773 \\
\hline Visitors & 07,590 & 77,045 & 10,109 & 341 & 62 & 18 & 9 & 4 & 2 & & & & & & & & & & & 619 \\
\hline DOF Olfices & 2,058 & 1,544 & 490 & 21 & 3 & & & & & 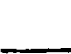 & & & & & & & & & & 29 \\
\hline $\begin{array}{l}\text { TOTAL } \\
\text { EXPOSURES }\end{array}$ & 173,055 & 122,099 & 39,493 & 5,243 & 2,736 & 1,262 & 700 & 1,117 & 389 & 16 & & & & & & . & & & & 8,024 \\
\hline $\begin{array}{l}\text { TOTAL } \\
\text { PERSON-REM }\end{array}$ & & & 1,975 & 918 & 1,026 & 789 & 612 & 1,676 & 972 & 56 & & & & & & & & & & 8,024 \\
\hline
\end{tabular}


the analysis of general exposure trends. The cumulative lifetime dose equivalent for terminating DOE employees would be available from the termination occupational exposure report.

Limitations

Limitations of the current system were identified in a previous report. The current system cannot quickly and efficiently provide the information DOE needs. Although extensive records are maintained at DOE sites, there are no requirements for their availability or retrievability. No record is kept showing the location of occupational histories for present DOE or DOE contractor employees. Only terminated DOE and DOE contractor employees and visitors who were monitored for occupational radiation exposure are identified.

Inconsistent interpretations of DOE Order $5484.1^{(3)}$ result in inconsistent data input to REIRS. For example, DOE Order 5480.1 , Chapter $X^{(4)}$ defines a positive measurable exposure as "any recorded exposure greater than the minimum sensitivity of the personnel monitoring device." Some contractors include individuals who do not receive a positive, measurable exposure in the "less than measurable" category, while others include them in the "less than 0.1 rem" category. The latter category is currently used in man-rem calculations; the former is not.

Contractors also vary in their policy concerning individuals whose exposures are reported to REIRS. Monitoring is required where the potential exists for an individual to receive a dose or dose commitment in any calendar quarter in excess of $10 \%$ of the quarterly or annual occupational guidelines detailed in DOE Order 5480.1, Chapter XI. Depending on the administrative policy of the contractor, monitoring may also be provided for individuals, such as clerical staff, who are not involved in work activities that could result in a potential radiation exposure. Currently, contractors may report the distribution of whole-body exposures for only those individuals for whom monitoring is required, or for all individuals for whom monitoring is provided.

Inconsistent practices are used in the reporting of a single deposition. Some contractors report a deposition only in the year it is detected. 0 ther 
contractors submit a report each year when routine analysis shows a deposition (whether a new deposition or a previously reported deposition) greater than the defined level.

The collective dose equivalent currently reported in the DOE annual employee exposure report is a calculated number rather than the actual collective dose equivalent. The calculation is performed by multiplying the number of individuals reported by the sites in each dose range by the midpoint of that range and then summing the products. This procedure allows an estimation of the collective dose equivalent without knowledge of each individual's annual dose. Because the actual mean dose equivalent in each range is most likely not equal to the arithmetic mean utilized, the resulting collective dose equivalent may be inaccurate.

The facility class has inappropriately included a "visitor" category. In some instances, the dose received by a DOE contractor employee during a visit to another site was reported by both the individual's employer and the site visited. This practice has recently been corrected so that the only reported radiation dose for a DOE contractor employee is reported by the employee's contractor office. Also, some contractors classify an individual as a visitor whenever the person works in a facility to which he is not normally assigned. These practices have resulted in an individual's exposure being included in more than one summary report to the repository and have inflated the number of individuals reported as visitors.

\section{ALTERNATIVE 2 - CLARIFICATION OF DEPARTMENT OF ENERGY ORDER FOR CURRENT SYSTEM}

Input

Department of Energy contractors would continue to submit to REIRS the summary exposure information required by DOE Order 5484.1. The primary difference would be that specific sections of the order would be clarified. This clarification is expected to result in more consistent (and therefore more accurate) input data from the individual sites. The recommended clarifications are: 
1. Annual Summary of Whole-Body Exposures

a. Define "positive, measurable occupational exposure." Differences in hOW DOE contractors report exposures in the "less than measurable" and "less than 0.1 rem" categories create inaccuracies in the annual person-rem calculations, as the "less than 0.1 rem" category is used in the man-rem calculation and the "less than measurable" category is not. The "less than measurable" category should be changed to "less than 50 mrem" and should not be included in the collective dose-equivalent calculation. Background not attributed to occupational exposure should be subtracted from all measurements.

b. Increase the specificity of facility categories. Current input from sites classifies about three-fourths of the personnel dose information in the nonspecific categories of other (approximately 10\%), visitors (approximately 50\%), or general research (approximately 25\%). (5) Additional facility classes should be added and space left on the input forms for sites to identify the facilities placed in the "other" or "general research" categories. The category "visitor" should be removed from the facility class.

c. Clarify the visitor classification. At present, the majority of monitored persons may be classified as visitors for certain sites when, in fact, they are permanent employees simply visiting a monitored area other than the one to which they are permanently assigned. Visitors should be classified as non-DOE, DOE offsite, or DOE onsite.

\section{Internal Exposure Summary}

a. Clarify instructions. The requirements for when a report should be submitted should be clearly described. An ad hoc committee should be established to review this issue. 
b. Provide instructions regarding the time period of the reported dose. Guidance is needed on reporting a deposition when the deposition date or the time period of deposition is not known. Unless the deposition date is documented otherwise, it should be the day after the last measurement.

3. Termination Report

a. Define "residual internal deposition." The deposition by organ and radionuclide should be defined as the residual deposition upon termination.

b. Include internal deposition date. The internal deposition information should include the date(s) of deposition(s).

Attributes

The clarification of the present DOE Order 5484.1 would result in more uniform submission of data from the sites. This input would provide a more consistent data base for the annual radiation exposure summary reports.

$\underline{\text { Limitations }}$

Clarification of the DOE order would not provide the additional information needed to expand the present annual summary reports; nor would it identify DOE and DOE contractor employees and badged visitors to DOE and contractor facilities. This alternative would require that DOE Headquarters commit significant staff time to reviewing and rewriting the present orders to make them concise and explicit. The implementation of these changes at the contractor sites and at the records library would probably require a minimal staff commitment, depending on the extent of the changes.

\section{ALTERNATIVE 3 - INCREASED SUMMARY INFORMATION FROM SITES}

Input

Under this alternative, sites would have to submit to the records library currently required forms (i.e., annual exposure summaries and termination exposure reports) plus additional summary information. The additional information 
would include frequency distributions of annual and lifetime exposure according to age, sex, facility type, and occupation. Examples of the types of information that would be submitted are shown in Appendix A.

Attributes

The increase in summacy information would expand the annual summary report on occupational exposures. Additional trend analyses would aid in assessing the status of DOE radiation protection programs and the impact of proposed regulations.

\section{Limitations}

Few contractors currently have the capability to obtain from their records the type of statistical information that would be required under this alternative. (Table 3 summarizes the frequency distributions that are currently available at some DOE sites.) Therefore, most sites would have to make significant changes in their records systems. A number of computer programming changes would be needed. A further limitation to this alternative is that DOE and DOE contractor employees and badged visitors would still not be identified.

TABLE 3. Frequency Distributions Developed Directly frgm Records
at 43 Department of Energy Contractor Sites at 43 Department of Energy Contractor Sites

Frequency Distributions Developing Frequency

Annual statistical distribution by facility type Annual statistical distribution by occupational class Distributions Cumulative lifetime whole-body dose statistical distribution by facility type

Cumulative lifetime whole-body dose statistical distribution by occupational class

Age versus annual dose distribution Age versus lifetime cumulative dose Sex versus annual dose distribution Sex versus lifetime cumulative dose Sex and age versus annual dose Sex and age versus lifetime cumulative dose Craft versus annual dose distribution Craft versus lifetime cumulative dose

(a) This information was obtained from a survey conducted in $1980 / 81$. 
$\underline{\text { Input }}$

Annual dose information on individuals would be submitted to the records library so that the occupational exposure histories for all DOE and DOE contractor employees would be available in one location. Termination reports would not be required. New orders would be written to identify the information to be submitted to the records library. Input parameters would include as a minimum:

1. contractor information
a. contractor code
b. DOE field office code
c. date of report

2. employee information
a. name
b. social security number
c. birth date
d. sex
e. occupation
f. facility class
g. hire date
h. termination date
i. date of death, if known
j. employment code

3. external exposure
a. year(s) of reported dose
b. area of body (i.e., eyes, skin, whole body, etc.)
c. total external dose (rem) - penetrating
d. total external dose (rem) - skin
e. total neutron dose (rem)
f. extremity exposure (rem)
g. cumulative whole-body exposure (rem) - estimated lifetime dose


4. internal exposure
a. year(s) of reported dose
b. $\operatorname{date}(s)$ of deposition
c. $\operatorname{argan}(\mathrm{s})$
d. nuclide(s)
e. deposition quantity $(\mu \mathrm{C} i)$, if known, and assigned dose.

A centralized individual records system could be developed in one of several ways. The two most likely means are 1) the duplication of all individual records from each site for provision to the records library, and 2) the development of a computer network system to allow interactive queuing of each site's computer file by the records library. In either case, if the records library were to maintain the official occupational exposure records, then all supporting information would have to be available there. However, any data concerning an individual's exposure history would have to be confirmed at the site(s) where the individual worked.

\section{Attributes}

Providing the records library with data on individual annual doses would greatly expand the capabilities of the system. Greater consistency in data interpretation would result, as well as the flexibility to analyze different parameters. Information needed to respond to special requests would be readily available in a central location.

This option would allow the expansion of the information for annual exposure summary reports, and the identification of DOE and DOE contractor employees and badged visitors. Annual collective dose-equivalent calculations would be made from actual dose information. The use of a computer queuing system would make historical information readily available.

\section{Limitations}

The centralized system would require that all sites maintain identical exposure records systems and compatible computer systems to allow a networking capability for interactive data exchange. In addition, there would be a duplicative effort at the site and the records library, as complete individual exposure histories would be maintained at each site. The DOE would need to 
revise the DOE order so that the occupational dose records system would be flexible enough to meet the needs of each DOE site.

Although this alternative would make possible an assessment of cumulative whole-body employee dose to date, information on any dose incurred while individuals were employed at non-DOE or non-DOE contractor facilities might not be available. The privacy and confidentiality issue is unclear, especially because the Privacy Act and the Freedom of Information Act are often in conflict and the legal issue has not been fully ressolved. Sensitive data on personnel would be stored at both the sites and at the records library, and absolute control of access to these records would be difficult.

\section{ALTERNATIVE 5 - ANNUAL DOSE SUMMARY AND LOCATOR FILES SYSTEM}

Input

This alternative would require that sites submit annually two locator files, and files containing internal and external dose information on all monitored employees and visitors. Termination reports would not be required. The required inputs and their purpose are detailed below. Sites would be encouraged to transmit the data via available computer technology using a specified format.

\section{Locator Files}

The purpose of the locator files would be to identify whether an individual has worked at or visited a DOE facility. One file would be maintained for employees and another for badged visitors.

Employee Locator File. This locator file would identify whether an individual has worked at a DOE site as either a DOE or DOE contractor employee or a resident nonemployee. (Resident nonemployees are non-DOE/DOE contractor employees, such as telephone repair or copier maintenance personnel, who have routine access to a site.) This file would not identify whether the individual was a radiation worker and would not contain any occupational exposure information. It would provide a centralized data base that could be used to track transient and support personnel and to identify the specific sites to 
contact for individual exposure histories in the event of litigation or a request for information. The employee information submitted would include:

1. full name

2. social security number or other unique personal identifier

3. date of birth

4. most recent date of hire

5. date of termination

6. sex

7. contractor or DOE field office

8. site location

9. employment code (DOE or DOE contractor or resident nonemployee).

Two separate records would be submitted if an individual terminated and was then rehired in one calendar year.

Badged Visitor File. This file would aid in identifying visitors to DOE field offices and contractor sites who have been monitored for potential exposure. The information submitted would include:

1. full name

2. social security number or other unique personal identifier

3. date of birth

4. date first badge was issued

5. date last badge was issued

6. contractor or field office sponsor.

Annual Dose Files

The data submitted for the annual dose files would be similar to that required for Alternative 4. However, under this alternative, individual occupational exposure histories would be maintained only at the respective sites; data for the preceding year would be submitted to the records library each year for radiation workers only, and without any personal identification. From that data, the records library would prepare summary tables for the annual report similar to those in Appendix A. Any information that was intended for publication and that identified a site would first be sent to the site for review. 
Under this system, internal and external dose data would be submitted as one file; however, they are described separately below.

External Dose File. The information submitted would include:

1. sequence number - A sequence number would be assigned to each individual by the site when the record was transmitted. The sequence number would allow the site to correct data input for an individual after the site's entire file was sent, while maintaining personal identification of data at the site only.

2. facility - The type of facility in which the individual is employed would be specified. If a site was in doubt as to the appropriate facility class, it would be identified with the assistance of the records library personnel. The facility type would be chosen from the following list:
a. reactor
b. fuel fabrication
c. fuel reprocessing
d. fuel enrichment
e. weapons fabrication
f. weapons testing
g. waste processing/management
h. nuclear research
i. nonnuclear research
j. accelerator
k. office or administrative
1. general plant.

A category "other" would be included for nonspecified facilities, and space would be provided on the input form to define the facility type. If an individual worked at two or more facilities, the exposure would be attributed to the facility where the highest probability for exposure exists. If this distinction was not possible, the exposure would be attributed to the facility where the individual was assigned at the time of the report. 
3. occupation - Each individual's occupation would be selected from the following list. An "other" category would be included, with space provided on the input form to further clarify the information.

a. administrative/supervisory

office worker

manager

b. technical support

chemical operator

metallurgical operator

analytical lab technician

c. research and development

engineer

chemist

scientist

metallurgist, etc.

d. radiological support

health protection/radiation safety professional

(radiation protection technician)

e. support personnel

technican

plumber/pipefitter

welder

electrician

carpenter

painter

mechanic

machinist

general laborer

f. nontechnical support

security personne]

clerical worker

materials manager

janitor 
g. other professionals

4. employment code

a. DOE field office or headquarters employee

b. resident nonemployee

c. DOE contractor employee

d. visitor who received more than $25 \mathrm{mrem} / \mathrm{visit}$

5. sex

6. year of birth

7. annual radiation doses in rem

a. total annual external whole-body dose - The total annual external occupational dose would be reported (excluding neutrons, which are reported in 7d). Background, not related to occupational exposure, would be subtracted from the total exposure. All recorded exposures would be reported; however, any recorded exposure less than 50 mrem would not be included in the annual collective dose summary calculations.

b. skin - The skin dose would be submitted only for those individuals who are so monitored, and would be the dose reported at $7-\mathrm{mg} / \mathrm{cm}^{2}$ depth.

c. tritium - Tritium would be reported only for those monitored.

d. neutron - The neutron dose would be reported only for those monitored.

e. extremity dose - The assigned extremity dose would be reported only for those monitored.

8. lifetime external dose - Both the cumulative dose received at the DOE or DOE contractor site and an estimate of the lifetime whole-body dose (exposure) would be reported.

Internal Dose File. The current national and international recommendations for internal dosimetry, made by a scientific advisory group, are being reviewed by a DOE Ad Hoc Committee. Consequently, the internal dose file 
would be developed in two phases, with an eventual goal of internal dose analyses that are consistent with national and international recommendations.

Phase I would begin at the inception of the system. During this phase, data on internal depositions would be submitted to the records library on a regularly scheduled basis. The data would have to meet the criteria for internal exposure shown in Table 4. The depositions reported could then be compared in table form, as well as the depositions in exposure ranges by year in the form of trend charts. Data submitted from the sites for each deposition case would include:

1. known or assumed date of deposition - If more than one deposition had occurred during the year, the date of the major deposition would be reported. Chronic exposures would be indicated in an appropriate manner.

2. radionuclides(s)

3. deposition/estimated dose

a. For long-lived and/or well-retained radionuclides: The estimate of the initial pulmonary burden and the systemic burden estimate during the year would be reported for a 11 cases meeting the criteria defined in Table 4 for which evaluations have been made. Both the incremental deposition during the year and the total accumulated systemic burden would be reported.

b. For short-lived and/or not well retained radionuclides: The estimated calendar-year dose to the lungs and other organs would be reported according to the criteria in Table 4.

Phase II would involve a review of internal dosimetry practices. Contractors might eventually have to report internal exposure in a format that would permit it to be combined with external exposure data. Additionally, a method to distinguish between persons with no internal exposure and those with a confirmed but extremely smali lung or systemic deposition might be required. 
TABLE 4. Initial Reporting Criteria for Internal Exposure: Phase I Criteria for Long-Lived, Wel1-Retained Radionuclides ( $T$ eff $>1$ year)

Lung Burdens

Any confirmed pulmonary burden $>10 \%$ of the maximum permissible lung dose. The lung burden shall be reported in units of $\mu \mathrm{Ci}$ and in rem for the calendar year.

For certain radionuclides, the current state of the art will not permit detection at this level. In some cases, the detection level may be on the order of 2 to 3 times the permissible lung burdens.
Systemic Burdens

Any confirmed systemic burden $\geq 10 \%$ of the maximum permissible body burden. If prior depositions of that radionuclide have been incurred, both the portion due to the new intake and the total accumulated systemic burden shall be reported in units of $\mu \mathrm{C} i$ and rem for the calendar year. Also, the major organ/tissues at risk will be reported.

Criteria for Short-Lived or Not-We11-Retained Radionuclides ( $T$ eff $\leq 1$ year)

Lung Burdens

Any confirmed pulmonary burden that will result in a dose to lung tissue $>0.75 \mathrm{rem}$ in any 12 -month period. The dose shall be reported as rem for the calendar year.
Systemic Burdens

Any confirmed systemic burden that will result in a dose to any organ $>1.5 \mathrm{rem}$ in any 12-month period. The dose shall be reported as rem for the calendar year. If more than one organ received a dose of $\geq 1.5$ rem, all shall be reported.

At the present time, capabilities for making this distinction do not exist. The concepts presented in Publications 26 and 30 of the International Commission on Radiological Protection (ICRP) ${ }^{(6,7)}$ were an attempt to resolve part of the problem; however, they have not proven practicable. The International Atomic Energy Agency has established a committee to investigate the problem and to establish some practicable resolution. The National Council on Radiation Protection and Measurements is also reviewing this matter. With many qualified groups reviewing the problem and making recommendations, an attempt to resolve the problem at this time would be premature. However, DOE should appoint a committee of applied health physicists to study the problem in depth, determine the probable impact of proposed solutions, and make recommendations to DOE. 
Attributes

With the annual dose summary and locator file system (ADSLF), an up-todate list of employees and badged visitors at DOE and DOE contractor sites would be maintained in the locator files to permit the identification of the DOE offices and/or DOE contractors that each individual worked for or had visited. The file could be accessed by individual name, social security number, DOE field office, or DOE contractor. Because the file would be developed prospectively, information on employees who had been employed prior to the system's initiation might not be available at first; however, as any of this information was accumulated, the sites would be encouraged to submit it to the locator files.

Input from the individual sites to the records library would be used to generate the summary data for the DOE annual report on radiation exposure. Individual dose information would be used to calculate the collective dose equivalent, both for each site and DOE-wide by selected occupations, facilities, etc. Dose distribution by sex and age would be available from the data. Examples of the summary data that would be produced by the records library are given in Appendix $A$.

A main advantage of this system would be that additional information could be developed from the dosimetric data base at a relatively low cost. The use of the actual individual dosimetry data in summary determinations would provide more accurate information about the DOE contractor sites than the current system provides, and additional information from the data files could be produced with little impact upon the sites.

\section{Limitations}

The cost of implementing ADSLF would be substantial; however, the primary costs (for developing computer programs) would be at the records library. At sites that presently have a computer-based system (approximately $50 \%$ ), the software would have to be modified to permit the transmission of information in a format compatible with the ADSLF system. 
Input from the sites would consist primarily of information that should normally be found in an adequate dose record system. The major change would entail establishing a method for identifying the employees and visitors. This effort would involve cooperation between different groups at each site, because a 11 DOE and contractor personnel and visitors are not radiation workers. The site costs for implementing ADSLF would depend upon each site's methods of maintaining employee records and dose records. Substantial changes might be required at some sites.

Considerable time would be required at the records library to develop the programs for data management and analysis. Also, the development and issuance of new DOE orders would be required. 


\section{COST-BENEFIT ANALYSIS}

\section{COST-BENEFIT TECHNIQUES FOR ANALYSIS OF ALTERNATIVES}

A cost-benefit analysis of the five alternatives for a radiation exposure information system was performed. This procedure required three steps:

1. development of a benefits matrix

2. cost analysis

3. calculation of a cost-benefit ratio.

Input from DOE contractors and the Ad Hoc Committee was used in the performance of this analysis.

\section{Benefits Matrix}

The benefits matrix used is shown in Table 5. The benefits of each alternative were assessed by the extent to which the alternative satisfied the criteria for an occupational radiation exposure information system (the criteria discussed earlier in this report). The criteria were listed in the left hand column of the benefits matrix. Some criteria were considered more important than others, so a "weight" was established for each. Then, the degree to which each alternative met each criterion was estimated and given a percentage. For example, it was estimated that Alternative 4 would very adequately satisfy criterion 1, so a $90 \%$ figure was given. The value assigned each alternative was the product of the weight and the percent.

An ideal alternative would accumulate a total value of 81 . It would be $100 \%$ effective in meeting the criteria. The effectiveness of each alternative was shown as its total value (or benefit factor) compared to 81 , and was expressed as a percent. The benefit factor was then used in the cost-benefit analysis.

\section{Cost Analysis}

A cost analysis for each alternative was performed using data submitted by the Ad Hoc Committee and the DOE contractors. Implementation and operating costs were considered. Costs provided are for comparison purposes only and should not be considered as absolute implementation costs. Included in the analysis were costs for the life cycle of the software, as well as for hardware. 
TABLE 5. Benefits Matrix

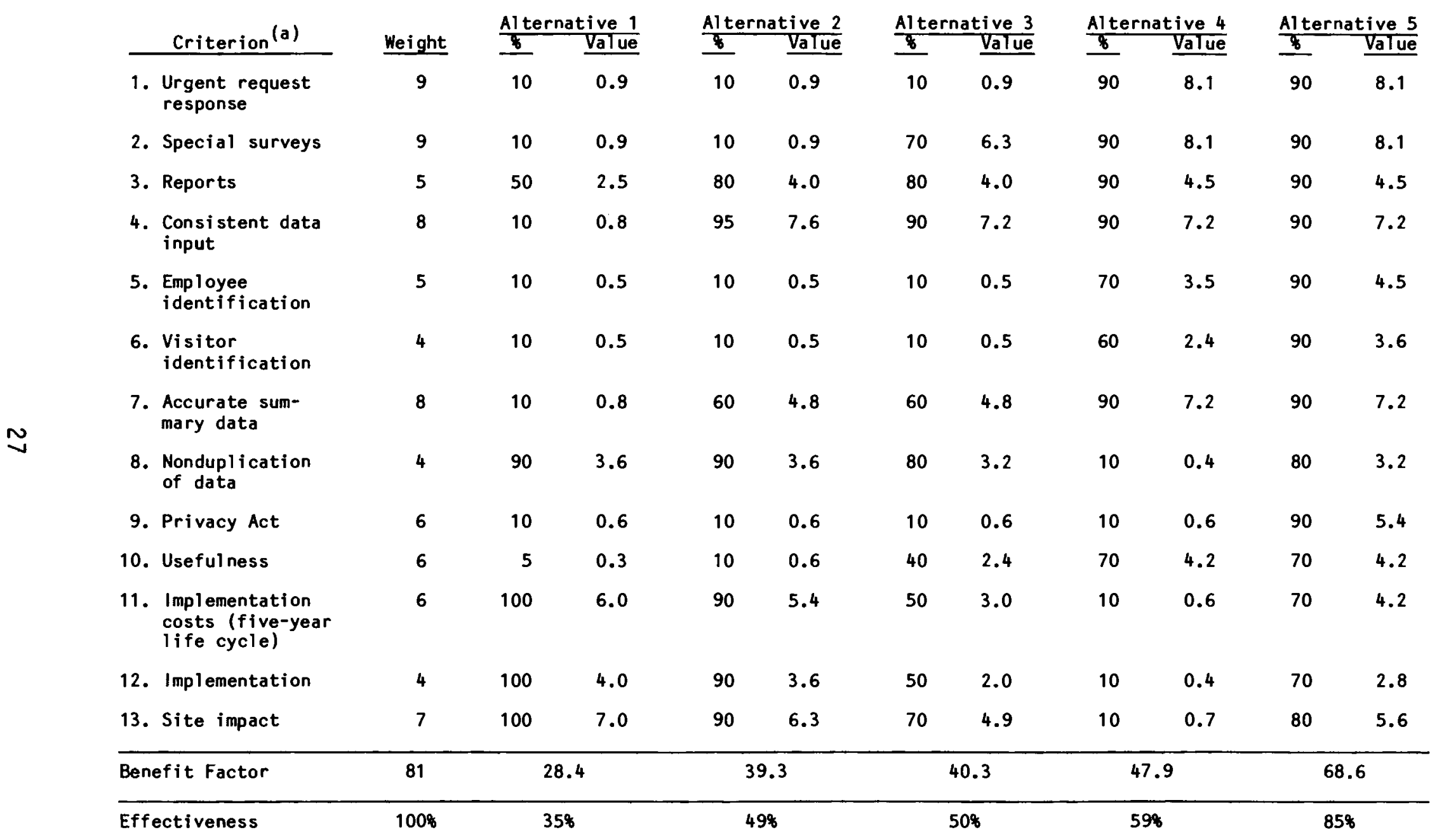

(a) Discussed in detail in section: Criteria for Occupational Radiation Exposure Information System. 
Computer systems typicaliy have a life of between 5 and 10 years, depending on their complexity. Since REIRS has been in operation since 1968, it could be assumed that an alternative to REIRS would last for about 10 years. However, with the very rapid growth of computer technology, a new system might need a review sooner. For this reason, a 5-year life cycle was used in the analysis.

Cost is incurred during the life cycle of software in the following areas:

1. preliminary planning and cost evaluation

2. system analysis and design

3. program design, code, and test (implementation)

4. system integration and test

5. system installation and turnover

6. program maintenance.

Only those costs that differed among the five alternatives were considered in this cost analysis. Thus, the projected costs reported must be used for comparative purposes only and not for budgeting purposes.

Table 6 lists the implementation and annual operating costs to the contractor sites and to the records library for each alternative. Table 7 gives the 5-year life-cycle cost based on the information in Table 6. Costs in the first year are those for initial implementation and for one year of operation.

TABLE 6. Estimated Costs for Each Alternative, Thousands of Dollars

\begin{tabular}{|c|c|c|c|c|}
\hline \multirow[b]{2}{*}{ Alternative } & \multicolumn{2}{|c|}{ Site Costs } & \multicolumn{2}{|c|}{ Records Library Costs } \\
\hline & Implementation & Annual & Implementation & Annual \\
\hline 1 & 0 & 5 & 0 & 75 \\
\hline 2 & 10 & 10 & 15 & 80 \\
\hline 3 & 50 & 15 & 50 & 100 \\
\hline 4 & 50 & 30 & 400 & 300 \\
\hline 5 & $75^{(a)}$ & 5 & 100 & 100 \\
\hline
\end{tabular}

(a) Represents the implementation cost at a site where substantial changes in recordkeeping would have to be made. 
TABLE 7. Five-Year Life-Cycle Cost Analysis (a-e)

\begin{tabular}{|c|c|c|c|c|c|c|}
\hline \multirow[b]{2}{*}{ Alternative } & \multicolumn{6}{|c|}{ Cost, Thousands of Dollars } \\
\hline & Year 1 & Year 2 & Year 3 & Year 4 & Year 5 & Tota] \\
\hline 1 & 200.0 & 214.0 & 229.0 & 245.0 & 262.2 & 1150.2 \\
\hline 2 & 595.0 & 353.1 & 377.8 & 404.3 & 432.6 & 2162.8 \\
\hline 3 & 1775.0 & 508.2 & 543.8 & 581.9 & 622.6 & 4031.5 \\
\hline 4 & 2700.0 & 1123.5 & 1202.2 & 1286.3 & 1376.3 & 7688.3 \\
\hline 5 & 2200.0 & 240.8 & 257.6 & 275.6 & 294.9 & 3268.9 \\
\hline
\end{tabular}

(a) The cost components used are implementation and annual operating costs at contractor sites and at the records library.

(b) Calculations are based on 25 major contractor sites.

(c) Annual operating costs are escalated at an annual rate of $7 \%$, compounded annually.

(d) No DOE Headquarters staff costs are included.

(e) Because the work is expected to be contracted out, the estimates use fully burdened contractor rates, with allowances for management and other overheads.

Each succeeding year's costs are only the operational costs, escalated at an annual rate of $7 \%$, compounded annually. These costs are based on the information in Appendix B.

Cost-Benefit Ratio Analysis

Cost-benefit ratios are an index calculated by dividing costs (usually in dollars) by benefits (often in dollars but sometimes in other units). The objective is to achieve a cost-benefit ratio of less than 1 . The benefit factor used here results in a ratio that does not mean anything on its own, but can be used for purposes of comparison and can aid in identifying alternatives that are not cost effective.

In this report, the ratio was obtained by dividing the 5-year life-cycle cost by the factor derived from the benefits matrix. The ratios for the five alternatives are shown in Table 8 . The preferred alternative would be the alternative with the lowest ratio. 
TABLE 8. Cost-Benefit Ratio Analys is (a)

\begin{tabular}{|c|c|c|c|}
\hline Alternative & $\begin{array}{l}5 \text {-Year Cost, } \\
\text { Thousands }(b) \\
\text { of Dollars }\end{array}$ & Benefit Factor $(c)$ & $\operatorname{Ratio}^{(\mathrm{d})}$ \\
\hline 1 & 1150.2 & 28.4 & 40.5 \\
\hline 2 & 2161.8 & 39.3 & 55.0 \\
\hline 3 & 4013.5 & 40.3 & 100.0 \\
\hline 4 & 7688.3 & 47.9 & 160.5 \\
\hline 5 & 3268.9 & 68.6 & 47.7 \\
\hline
\end{tabular}

(a) Cost of DOE Headquarters staff not included.

(b) Costs are from Table 7.

(c) Benefit factors are from Table 5.

(d) Ratio $=$ cost $\div$ benefit factor.

\section{RESULTS OF COST-BENEFIT ANALYSIS}

Al ternative 1 - No Change in Current System

As shown in Table 5 , the present system meets satisfactorily only two of the ten information criteria: providing information for reports, and nonduplication of information. The quality of the data in some reports has been questioned, so even the meeting of this criterion is doubtful. The development criteria (criteria 11-13) are considered as being 100\% satisfied by the current system, as its continuation would involve no implementation costs or site impacts. The comparatively low cost of maintaining the current system (Tables 6 and 7) contributes to the cost-benefit ratio for this alternative being the lowest of the five cost-benefit ratios (40.5, from Table 8); however, the overall effectiveness of this alternative in meeting the criteria is also the lowest for all the alternatives (35\%, from Table 5).

Alternative 2 - Clarification of Department of Energy Order for Current System

This alternative would improve the quality of the raw data submitted to the records library but would still meet satisfactorily only four of the ten primary information criteria, as shown in Table 5 . The satisfying of the 
development criteria would be only slightly less than the $100 \%$ of Alternative 1. The overall effectiveness of this alternative in meeting the criteria would be $14 \%$ above that of Alternative 1 .

The cost of implementation at the sites would be minimal, as would the increase in annual operating costs relative to those for Alternative 1 (see Table 6 ). The cost of implementation at the records library would also be minimal (about $\$ 15 \mathrm{~K}$ ), and the records library's annual operating costs would increase only slightly over current costs (because of the potential increase in the use of the system).

The cost-benefit ratio of 55.0 (Table 8 ) indicates that the cost impact for Alternative 2, compared to the cost of leaving the system as is, is minimal. However, the $14 \%$ overall improvement provided by the alternative is marginal.

Alternative 3 - Increased Summary Information from Sites

As under Alternative 2, DOE Headquarters would need to rewrite and expand DOE Order 5484.1. To comply with the changes, each site would have to modify its present procedures for the submission of information. Some sites might require a one-man-year effort, as shown in Table 6; however, in most instances the cost should be much less. Changes in the costs for the records library, compared with current costs, would be incurred primarily at implementation, with a slight increase in annual operating costs. Under this alternative, the information needed for reports would be provided, and the quality of the data would be improved over that of the current system (Table 5). However, the ability to locate employees and visitors and to respond to urgent requests would still be minimal to nonexistent. The overall effectiveness of this al ternative would be about a $15 \%$ improvement over the effectiveness of the present system, at a fairly high 5-year cost (about \$4.0M, from Table 7).

The benefit factor for this alternative is approximately equal to that of Alternative 2 (see Table 5). However, the cost of this system results in a relatively high cost-benefit ratio (100.0, from Table 8 ). 
Alternative 4 - Centralized Annual Individual Dose (Exposure) System

Most information criteria would be satisfactorily met by this alternative (Table 5). However, the initial development costs, implementation time, and site impact would be high. The annual operating costs would be higher than those for any other alternative (Table 6).

The overall effectiveness of this alternative (59\%, from Table 5) would be a $24 \%$ improvement over that of the current system. However, the 5-year cost of the alternative would be a factor of seven higher than the 5-year cost for Alternative 1 (Table 7 ). The cost-benefit ratio of 160.5 for this alternative is the highest of all the cost-benefit ratios (Table 8 ).

Alternative 5 - Annual Dose Summary and Locator Files System

As shown in Table 5 , the ADSLF alternative would satisfy all of the information criteria quite well and would be relatively straightforward in development terms. This information system would be more effective than any of the other alternatives (85\%).

Implementation costs at each site would result primarily from acquiring additional personnel data, reformatting the presently collected data, and transmitting the data directly or via magnetic tape to the data processing center managed by the records library. At sites where computerized record systems do not exist, the acquisition of a system or the purchase of intelligent terminals would be part of the implementation costs. The magnitude of this effort would vary from site to site, but would average about $\$ 75,000$ per site (Table 6). This cost, analyzed in more detail in Appendix B, includes costs associated with the two locator files.

At the records library, significant reprogramming of the processing programs and the system maintenance procedures would be required, as well as new analytical programs. The cost is estimated to be about $\$ 100,000$.

As Table 8 shows, the cost-benefit ratio for this alternative is low (47.7) and is comparable to that for Alternative 1. In addition to the favorable cost-benefit ratio, the ADSLF alternative offers the most improvement in system effectiveness. 
CONCLUSIONS AND RECOMMENDATIONS

The alternatives for a DOE-wide radiation exposure information reporting system that have been presented in this document can all be considered viable systems. The attributes, limitations, costs, and benefits of the respective alternatives have been addressed. Additional cost analyses that were performed for the alternatives are included in Appendix B. Table 9 is a brief summary of some of the key information that has been presented in this document. The table shows that three of the alternatives (no change in the current system, DOE-ordered clarification for the current system, and increased summary information from sites) do not meet the information criteria for an adequate system. From the cost standpoint, one alternative (the central individual dose (exposure) system) is the most costly but meets most of the information criteria. The ADSLF alternative meets the information criteria more fully and with a relatively small increase in overall costs. This alternative also has a favorable cost-benefit ratio. Based on this information, the ADSLF system is recommended as the proposed alternative for the DOE-wide radiation exposure information system.

The majority of the Ad Hoc Committee on Occupational Exposure Registry Upgrade concurred with this recommendation. However, the committee further recommended that, if a decision was made not to upgrade the DOE occupational radiation exposure system at this time, the present DOE Order 5484.1 be rewritten to clarify the document. Additionally, the committee recommended the establishment of a committee to provide guidance for the reporting of internal dose.

The implementation of the recommended alternative would require that modifications be made at the present REIRS site. Some of the cost aspects are discussed in Appendix $B$, and an analysis of telecommunications alternatives is presented in Appendix $C$.

The acceptance of the ADSLF alternative as the DOE-wide exposure reporting system should give added capabilities to DOE in responding to requests for information and should reduce the impact of special survey requests upon the 
TABLE 9. Summarized Assessment of Alternatives

Ability of Alternative to Meet Assessment Criteria

\begin{tabular}{|c|c|c|c|}
\hline \multicolumn{2}{|r|}{ Alternative } & Urgent Requests & Special Su \\
\hline 1 & $\begin{array}{l}\text { No Change in } \\
\text { current } \\
\text { system }\end{array}$ & $\begin{array}{l}\text { Limited to summary } \\
\text { data }\end{array}$ & Limited \\
\hline 2 & $\begin{array}{l}\text { Clarifica- } \\
\text { tion of DOE } \\
\text { Order for } \\
\text { Current } \\
\text { System }\end{array}$ & $\begin{array}{l}\text { Limited to summary } \\
\text { data }\end{array}$ & Limited \\
\hline 3 & $\begin{array}{l}\text { Increased } \\
\text { Summary } \\
\text { Information } \\
\text { from Sites }\end{array}$ & $\begin{array}{l}\text { Limited to summary } \\
\text { data }\end{array}$ & $\begin{array}{l}\text { Limited to } \\
\text { summary da } \\
\text { but additi } \\
\text { trend anal } \\
\text { possible }\end{array}$ \\
\hline 4 & $\begin{array}{l}\text { Central } \\
\text { Individual } \\
\text { Dose (Ex- } \\
\text { posure) } \\
\text { System }\end{array}$ & $\begin{array}{l}\text { Access to all } \\
\text { employee records }\end{array}$ & Avail lable \\
\hline 5 & $\begin{array}{l}\text { Annual } \\
\text { Dose Sum- } \\
\text { mary and } \\
\text { Locator } \\
\text { Files } \\
\text { System } \\
\text { (ADSLF) }\end{array}$ & $\begin{array}{l}\text { Limited to data from } \\
\text { past year, summary } \\
\text { data from previous } \\
\text { years, and iden- } \\
\text { tified employees }\end{array}$ & Available \\
\hline
\end{tabular}

annual sumnary
Comparative Implementation and Five-Year Operating Costs (millions of \$)

$\$ 1.2$

Limited to terminated occupationally

exposed personnel

and visitors

More consistency Limited to terminated

occupationally

exposed personnel

and visitors

reports

Limited to terminated occupationally exposed

Expanded annual summary reports personnel and

visitors

Annual summary and additional

All monitored personnel and visitors

$\$ 2.2$

$\$ 4.0$ reports

Expanded annual summary and addi summary and add 
sites. The development of a DOE and DOE contractor locator file would enable the rapid identification of personnel in the DOE system. Such a system would be beneficial for handling information requests on individuals by allowing the identification of the DOE sites where the individuals worked or visited. With many sites presently reviewing their historical records, the addition to this locator file of available information on past employees would increase the effectiveness of the system. Applicable information that is presently maintained in the current REIRS terminated employee exposure files would be moved into the employee locator file so that this historical information would be maintained. Finally, the recommended ADSLF alternative should be flexible enough to accept changes in radiation protection standards and policies.

Comments received from 26 respondents to the U.S. Department of Energy memorandum dated July 1, 1982, "Request for Review of Final Draft Report, Proposed Alternatives for a DOE-Wide Occupational Radiation Exposure Information System," are summarized in Appendix D. The comments were categorized, and responses to the general comment areas are provided. 


\section{REFERENCES}

1. Fix, J. J., G. J. Briscoe, J. M. Selby and E. J. Vallario. 1981. Overview of DOE Radiation Exposure Information Reporting System (REIRS). PNL-3450, Pacific Northwest Laboratory, Richland, Washington.

2. Fix, J. J., J. M. Selby and E. J. Vallario. 1981. Current Personnel Dosimetry Practices at DOE Facilities. PNL-3538, Pacific Northwest Laboratory, Richland, Washington.

3. U.S. Department of Energy. 1981. "Environmental Protection, Safety, and Health Protection Information Reporting Requirements." In DOE Order 5484.1, February 24, 1981, Washington, D.C.

4. U.S. Department of Energy. 1981. "Requirements for Radiation Protection." In DOE Order 5480.1, Chapter XI, Apri1 29, 1981, Washington, D.C.

5. U.S. Department of Energy. 1982. Thirteenth Annual Report of Radiation Exposures For DOE and DOE Contractor Employees - 1980. DOE/EP-0040/12, Washington, D.C.

6. International Commission on Radiological Protection (ICRP). 1977. Recommendations of the ICRP. ICRP Publication No. 26, Pergamon Press, oxford.

7. International Commission on Radiological Protection (ICRP). 1979.

Limits for Intakes of Radionuclides by Workers. ICRP Publication No. 30 , Pergamon Press, 0xford. 


\section{APPENDIX A}

EXAMPLE OF SUMMARY TABLES 
A. Distribution of Annual Whole Body Exposure

\begin{tabular}{|c|c|c|c|c|c|c|c|c|c|c|c|c|}
\hline Number of & Number & 0.05 & $>0.10$ & 0.25 & $>0.50$ & $>0.75$ & & & & & & Total \\
\hline Employees & Monitored & 0.10 & 0.25 & 0.50 & 0.75 & 1.00 & $>1-2$ & $2-3$ & $>3-4$ &, $4-5$ & $>5$ & Person-Rem \\
\hline
\end{tabular}

B. Distribution of Annual Whole Body Exposure by Sex

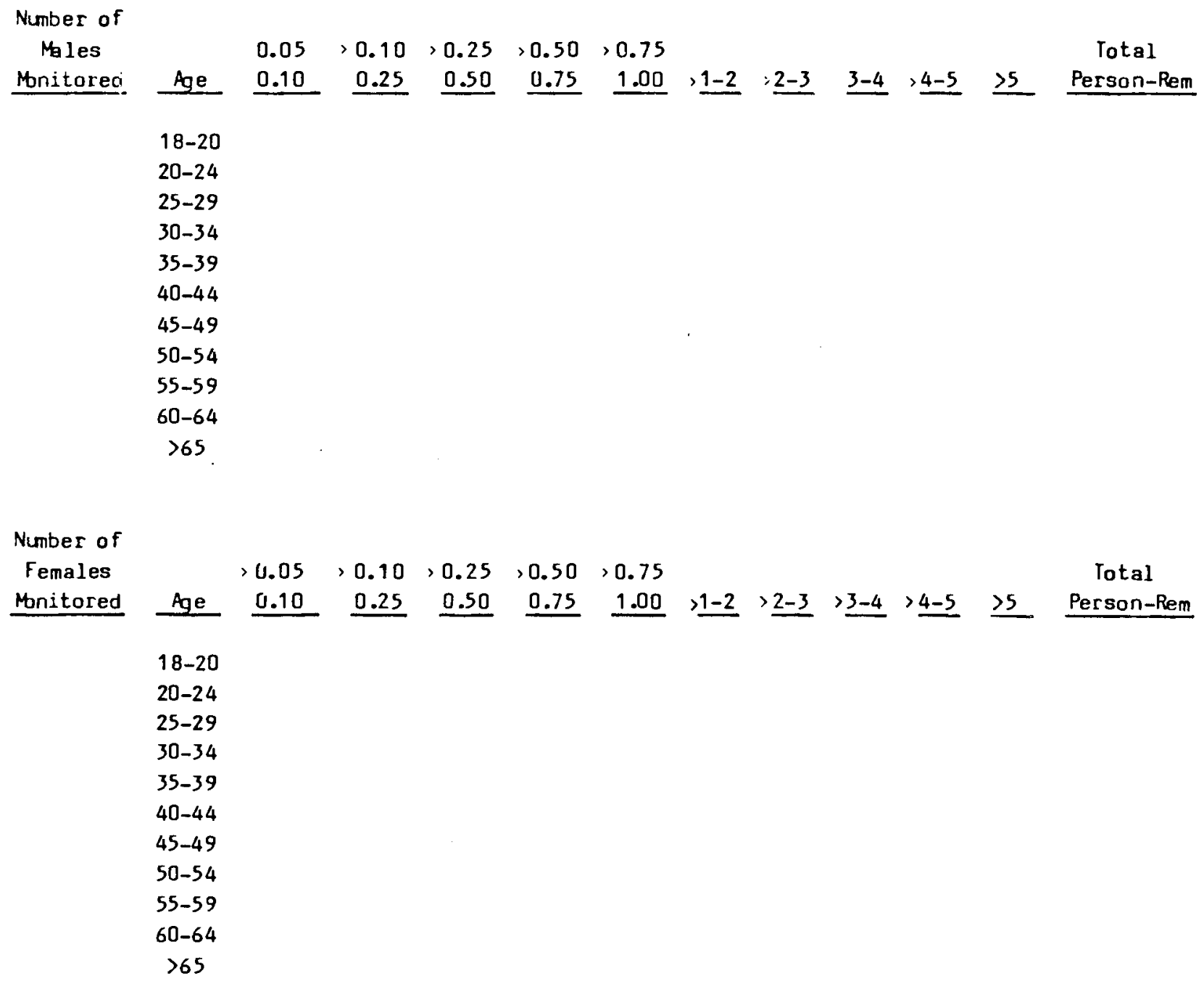


$\underline{X Y Z \text { Contractor (Contd) }}$

C. Distribution of Annual Whole Body Body Exposure by

$0.05>0.10>0.25>0.50>0.75$

Total

by accupation

$0.10 \quad 0.25 \quad \underline{0.50} \quad 0.75 \quad 1.0$

Person-Rem

Administrative/

Supervisory

Technical Support

Chemical Opera-

tors

Metallurigical

Analytical Lab

Technicians

Research and

Development

Radiological Support

Pi pefitters/

$\mathrm{Pl}$ umbers

Welders

El ectricians

Mechanics

Machinists

Ceneral Labor

Painter

Carpenter

Radiation Protec-

tion Technician

Non-Technical Support

Security

Clerical

Meterials

Management

Janitor

Research and Development

Halth Protection

Radiation Safety

Professionals 
D. Distribution of Annual Whole Body Exposure by Facility

$0.05>0.10>0.25>0.50>0.75 \quad$ Total

Facilit y Types

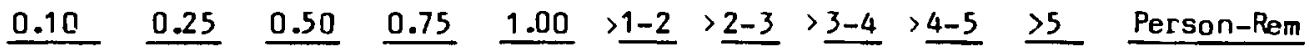

Reactor

Fuel Fabrication

Fuel Reprocessing

Fuel Enrichment

Weapons Fabrication

Weapons Testing

Nuclear Research

Non-Nuclear Research

Accelerator

Waste Processing Mt.

Office or Administrative

Ceneral Plant 


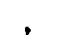

, 
APPENDIX B

COST ANALYSIS 
APPENDIX B

COST ANALYSIS

This appendix is an analysis of costs expected to be incurred as a result of implementing each of the five alternatives considered in this document. The costs considered are those associated with the life cycle of the software, hardware, and development. The software life cycle includes:

1. preliminary planning cost evaluation

2. system analysis and design

3. program design, code, and test (implementation)

4. system integration and test

5. system installation and turnover

6. program maintenance.

This analysis considers all the above items, but primarily examines those items which are different among the alternatives. For this analysis, one manyear is estimated to cost $\$ 60,000$.

\section{ALTERNATIVE 1 - NO CHANGE IN CURRENT SYSTEM}

Despite inconsistent interpretations of DOE Order 5484.1, a 11 contractors collect the information currently required for REIRS. This information is collected primarily to meet other responsibilities; the time and cost impacts imposed by REIRS are for the summarization and submission of the information, not for the collection of the data.

The present cost of submitting data to REIRS varies widely among the contractors because of differences in employee population, the types of work performed, and the nature of the facilities. At sites that presently have an automated system, summarizing and sending the information should be relatively straightforward. Ignoring computer time and other overheads (since it is basically a once-a-year exercise), the manpower effort is estimated to average one man-month (about $\$ 5,000$ ) per site. Sites without automated systems do not, in general, have the volume of data to warrant such a system. Low volumes 
of data are relatively easy to summarize and send manually. The manpower required at these sites is also about one man-month (about $\$ 5,000$ ).

The present operating cost for REIRS at EG\&G, Idaho, is about $\$ 75 \mathrm{~K}$.

\section{ALTERNATIVE 2 - CLARIFICATION OF DEPARTMENT OF ENERGY ORDER FOR CURRENT SYSTEM}

The purpose of this alternative would be to standardize the data submitted to the records library, not to significantly change the reporting, transmitting, and computing procedures. At the records library, for instance, the programs would still read "DOSE" and "UNITS," but the data input would be more consistent. At each site, work would be required to reorganize the present manual or automated systems to meet the changes in the DOE order. The amount of change needed would depend on the status of the present system at each site, since some systems may already comply with a new order.

It is estimated that a maximum of two man-months of effort, or $\$ 10,000$, would be required at each site to implement the basic programming changes or to make the necessary revisions to a smaller manual system. Assuming that the new DOE order would require greater quality assurance than before, an estimate of two man-months, or $\$ 10,000$ per year per site, is considered reasonable for on-going operating costs.

Only minor changes to the existing computer procedures at the records library would be necessary. Consequently, only a small implementation cost $(\$ 15,000)$ would be required. However, more work on an annual basis might be required at the records library since the more standardized and uniform data would be more usable than the current data is. Personnel at the records library might be expected to produce more analytical reports; however, because no additional data would be submitted by the sites, this work would not be too extensive. An operating cost of $\$ 5,000$ above the present $\$ 75,000$ would be adequate.

\section{ALTERNATIVE 3 - INCREASED SUMMARY INFORMATION FROM SITES}

Providing summary data, by its very nature, requires the analysis of larger quantities of data in detail. Consequently, at both automated and nonautomated sites, increased costs can be expected. Just under one man-year 
$(\$ 50,000)$ would be needed at each site to implement better summarizing procedures, while the existing REIRS code would need to be extensively modified but not totally rewritten (less than one man-year, $\$ 50,000$ ).

The subsequent operation of this system at each site is estimated to cost $\$ 15,000$ per year (three man-months, but a once-a-year activity), while the records library would need increased manpower and increased magnetic storage $(\$ 100,000$ per year $)$.

ALTERNATIVE 4 - CENTRALIZED ANNUAL INDIVIDUAL DOSE (EXPOSURE) SYSTEM

The main features of this option are that:

1. each site would report annually, but in detail and not in summary form

2. as in Alternative 2, changes in the DOE order would be necessary to ensure uniform data (this is even more critical with detailed data than with summary data)

3. although the centralized system would effectively retain duplicates of site records, thus indicating some duplication of effort, the duplication would involve computer effort, not manpower effort. Duplicating computer effort in these circumstances is not considered a major probiem.

As for the previously discussed alternatives, a site with an automated system would require about the same level of effort to comply as a site without an automated system, since the latter generally has fewer records. However, the standardization of data-reporting procedures across all sites would be an ongoing process with a large initial impact. The effort to implement this option at each site is estimated to require a little less than one full-time person $(2 \$ 50,000)$. The annual operational cost would be about $\$ 30,000$ because, although the effort would be extensive, it would only be required once a year.

At a centralized system, the vastly increased volume of data to be received would undoubtedly overload the current computing facilities. New 
programs would be required, as would additional disk and tape storage devices, and the processing and checking of data when received would be very manpowerintensive. Additional computing equipment is estimated to cost $\$ 100,000$ and an initial effort of five man-years (over a 2-year implementation period) is considered realistic, resulting in a total estimated implementation cost of $\$ 400,000$.

After implementation, the size of this computer project would require a staff of at least four--for data center management, programming, and analysis-with recurring magnetic media costs (tapes, disks, etc.) estimated at $\$ 60,000$. An annual operating cost of $\$ 300,000$ is estimated.

\section{ALTERNATIVE 5 - ANNUAL DOSE SUMMARY AND LOCATOR FILES SYSTEM}

There are a number of ways the ADSLF proposal could be implemented. One method is discussed below for the purposes of cost estimation, but it should not necessarily be regarded as the recommended system.

The method selected for discussion would require that each contractor site submit uniform and "standardized" individual data to the records library on an annual basis. The records library would also maintain, with contractor assistance, an employee locator file and a badged-visitor locator file.

Contractors with a computerized records system would need to reformat their present records and provide some programing to extract information in the required format for the records library. Sites that do not currently use SACNET (DOE's secure network) to transmit their summary data could either send magnetic tapes or use inexpensive communications hardware $(\$ 1000$ per site, if not already in place) to transmit via the public switching network (the telephone system).

Contractors without a computerized system would need to acquire one or procure an intelligent terminal ${ }^{(a)}$ compatible with the records library's

(1) An intelligent terminal is really a microcomputer; it can collect, store, and send data, can be programmed for simple tasks, and can drive attached peripherals like printers and floppy-disk drives. 
hardware. A set of basic software would be written to perform at least the records library's required functions.

There are three modules within this alternative, each needing a separate cost estimate:

1. annual summary dose file

2. employee locator file

3. visitor locator file.

Cost for Annual Summary Dose File

Contractors with automated systems would need about one man-year of effort using the above rationale, at a cost of $\$ 60,000$. Contractors without automated systems would need to acquire an intelligent terminal and associated peripherals (about $\$ 10,000$ ). The records library would program the intelligent terminals, which would require about two man-months $(\$ 10,000)$, but this cost would be effectively shared by those who needed the system.

Information from 1979 showed that, of 43 contractors surveyed, 26 had computerized systems of various types. A recent telephone survey indicated little change, although many sites without systems are now considering the acquisition of one. The recent survey indicated that a records system requiring the use of intelligent terminals would be consistent with the onsite plans of many contractors and, in many cases, would be the impetus for a site to obtain a terminal and upgrade its present system. This approach would pose very little organizational or financial impact at most sites.

At the records library, the present software would be modified, and new analytical programs would be written. Acknowledging the limited personnel resources at the current records library, an estimate of $\$ 100 \mathrm{~K}$ for implementation costs was assumed.

Annual operating costs of $\$ 100 \mathrm{~K}$ at the records 1 ibrary might be considered high for a "once-a-year" operation. However, contractors might use the new records library more frequently, and analytical programs would undoubtedly have to be modified and changed regularly. Considering the capabilities at the current REIRS and the known long-term DOE funding constraints, the figure of $\$ 100 \mathrm{~K}$ per year is considered an accurate estimate. 
Cost of Employee Locator File

The data that would be needed for this file is already maintained by personnel and/or payroll systems for most contractors. No radiation exposure or other health data would be required. Consequently, to extract the required data from existing systems and to submit the data on an annual basis to the records library would be a small task. The initial implementation work for this task is estimated to be two man-months, or $\$ 10,000$, with a negligible annual operating cost.

Cost for Visitor Locator File

The security procedures in place at most sites include the collection of most of the information required for this file. Because the volume of data needed would be small, the effort required would be approximately half that needed for the employee locator file. Each contractor is therefore assumed to expend $\$ 5,000$ to implement this task, with a negligible annual operating cost. Total Costs

In summary, the costs to contractors to implement the ADSLF alternative would be about $\$ 75,000$, with about $\$ 5,000$ in annual operating costs. The costs to the records library would be about $\$ 100,000$ for implementation and $\$ 100,000$ for the annual operation of the system. 


\section{APPENDIX C}

TELECOMMUNICATIONS ANALYSIS 


\section{APPENDIX C}

\section{TELECOMMUNICATIONS ANALYSIS}

Modern computer systems allow users to communicate with the host computer over dedicated or dial-up telephone lines. The communication may be simply to execute a program or conduct an inquiry against a data base, or it may involve the transmission of large quantities of data to and from the user. The volume of data and the frequency of transmission generally govern the type of communication established.

All of the alternatives to upgrade REIRS involve the transmission of data to a central site, presently at EG\&G, Idaho. The quantity of data transmitted and the frequency of transmission would vary for the different alternatives, but only one (the centralized annual individual dose (exposure) system) could require a frequency of transmission greater than once per year (if the records library had to respond to numerous requests for information). It would also involve the greatest volume of data transmission. Since this alternative represents a "worst case," some estimates of telecommunications costs are worth considering.

A "star" network such as that shown in Figure $1^{(a)}$ would consist of dedicated 4800-baud leased lines. Such a system would be a very expensive way of connecting the sites with the records library. The most expensive line would cost about $\$ 1700 /$ month, and the least expensive about $\$ 200 /$ month. At an average cost of $\$ 1000 /$ month across 43 sites, the annual cost would be over $\$ 500,000$.

A more efficient way to connect all the sites with dedicated lines is shown in the "multidropped" network in Figure 2.(a) Only four trunk 1 ines would be used, with short-distance drops from them to each site. The

(a) The purpose of the figures is to illustrate the concepts described. Therefore, not all sites are shown on the maps. 


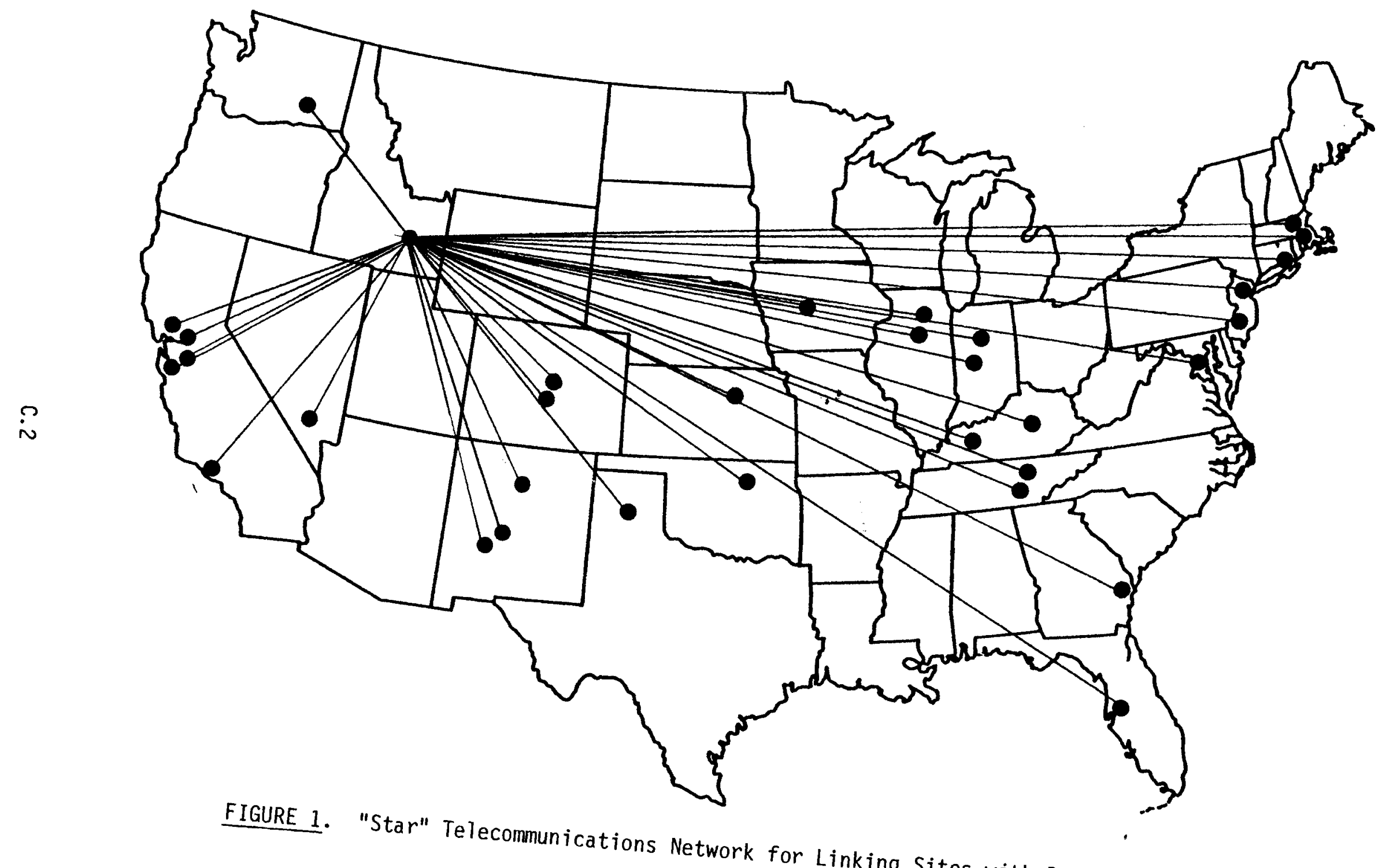

FIGURE 1. "Star" Telecommunications Network for Linking Sites with Records Library 


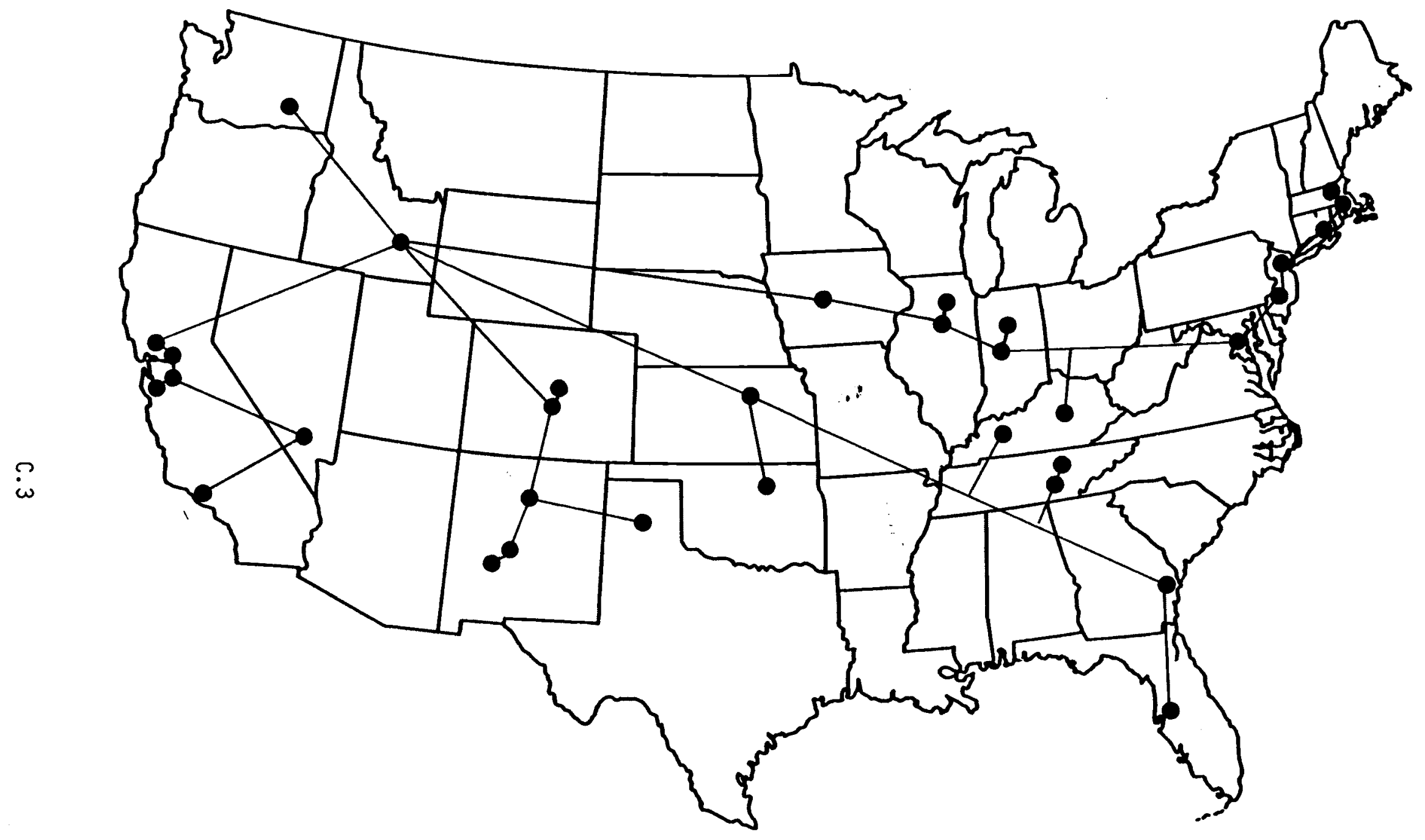

FIGURE 2. "Multidropped" Telecommunications Network for Linking Sites with Records Library 
estimated lease cost per month for this network is $\$ 9400$, with an annual cost of $\$ 112,800$. This would provide a better solution but would still require a heavy overhead.

The recommended ADSLF alternative could use either the "star" or the "multidropped" network to send the required data to the records library and to communicate with the analytical programs provided there. However, transmission would be required only on an annual basis, and the use of analytical programs would be unlikely to exceed one or two connections per week.

Rather than lease lines for this purpose, an inward wide-area transmission system (WATS) line (or an "800" number) could be established at the records library, allowing one user at a time to connect. Data could be transmitted at 1200 baud (about 100 characters per second). If each record contained 100 characters and there were 5000 records to send (per site), the total connect time would be about 90 minutes per site. However, the line (in fact, two lines) would have to be leased all year. Using the lowest published rates, there would be an initial fee of $\$ 30 /$ month/line plus a monthly usage fee (averaging, say $\$ 500 /$ month/line using an average of 5 hours connection per month). The total annual cost would thus be about $\$ 12,720$.

The utilization rate would be extremely low--perhaps four or five fully utilized days per year (rate 1.4\%)--and could not support leasing any form of communication line on an annul basis.

The least expensive alternative would be to continue the use of SACNET (DOE's own secure network) where possible, supported by the ordinary mailing of magnetic tape. The transmission time from any site to the records library should not exceed 5 days. Connections to the host to use programs and examine data could be accomplished over the federal telecommunications system (FTS) lines using 300- or 1200-baud (30-cps or 100-cps) dial-up devices, commonly used at the sites and presently supported (and controlled) at Idaho Falls. The cost of these connections would be the same as the cost of ordinary telephone calls for the same connect time over FTS lines. The use of SACNET would not incur any additional cost to the government. 
APPENDIX D

FIELD REV IEW COMMENTS AND RESPONSES 
APPENDIX D

\section{FIELD REVIEW COMMENTS AND RESPONSES}

This appendix summarizes the review comments received from 26 respondents to the U.S. Department of Energy memorandum dated July 1, 1982, "Request for Review of Final Draft Report, Proposed Alternatives for a DOE-Wide Occupational Radiation Exposure Information System." The comments were categorized, and responses to the general comment areas are provided. The authors wish to thank those individuals who provided both editorial and general comments concerning the draft report.

GENERAL COMMENTS ON THE REPORT AND THE NEED TO CHANGE THE CURRENT SYSTEM

Most respondents agreed that the current system needs to be upgraded and appreciated the opportunity to review the document. Of the respondents that directly voiced an opinion on the proposed alternatives, 12 agreed with the recommended alternative, 1 did not agree totally, and 5 felt that other alternatives or combinations of alternatives were better.

Two respondents stated that the report was biased toward Alternative 5 and lacked objectivity. The report was written to identify the alternatives that were discussed with the DOE Ad Hoc Committee and to develop, in detail, the alternative that had the approval of the majority of the committee.

\section{IMPLEMENTATION AND OPERATIONAL COSTS}

Five respondents expressed their concern that the estimated implementation costs for the five alternatives appeared to be low. However, the estimates for implementation given by 13 respondents ranged from minimal to $\$ 150,000$. Five felt that the $\$ 75,000$ estimated for the sites' implementation of the ADSLF alternative was low, and three indicated that it was more than adequate. The concern of most respondents was identifying the funds for the implementation of the alternative selected, since each site would have to identify specially designated funds (above the normal operating budget) and commit the manpower required for the alternative selected. 
With regard to the annual operating cost for the ADSLF alternative, two respondents estimated an increase over the cost of the present system. Several others indicated no impact on operating costs.

\section{RADIATION WORKER DEFINITION}

The definition of radiation worker used in this report was developed in order to identify true radiation workers and to eliminate personnel who are badged for convenience, not necessarily for compliance. The intention of the definition is not to direct the administrative practices at the sites but to standardize the data input to the records library. The definition was changed to reflect the current DOE Order 5480.1, Chapter XI, which requires monitoring based on quarterly standards. The definition does not attempt to establish an official DOE definition for radiation work nor to mandate any radiation dose limits for radiation workers, non-radiation workers, or the general public.

\section{EPIDEMIOLOGY}

Seven respondents expressed concern over the potential use of the proposed ADSLF alternative for epidemiology. The intent of REIRS and of any upgrade is to provide an overview of the radiation exposures at DOE facilities and to provide a data base that can be used to determine the impact of changes in radiation protection standards and practices. The use of the data base for epidemiological studies is not intended, because the information available would be insufficient for an accurate interpretation. The epidemiologist must be concerned with the monitoring practices associated with the assessment of the radiation dose, the health record of the individuals, other potential influences of the individuals' workstation and, foremost, the complete work history of each individual. The dose information files would be concerned only with the radiation protection aspect of the individuals. In order to prevent the potential misuse of the data, no personal information would be submitted by the sites with the dose information. However, the proposed alternative would allow the epidemiologist to locate similar types of data at each of the individual sites. 
OCCUPATIONAL AND FACILITY CODES

The identification of occupational and facility codes that are applicable to DOE activities is difficult. The respondents appeared to be concerned about the proposed lists. The listings provided were developed based on input from the Ad Hoc Committee and were not intended to be all inclusive. Further interaction with the sites will be requested to develop more extensive listings of applicable occupation and facility codes.

\section{$\underline{\text { DOSE FILES }}$}

Approximately $75 \%$ of the respondents commented on these files. The most common concerns were the definitions of the extremity and skin doses, and the availability of the estimated lifetime dose. These issues are recommended for further review by a DOE ad hoc committee.

\section{EMPLOYEE LOCATOR FILE AND BADGED-VISITOR FILE}

The major concern with respect to the locator files was the ability of the sites to provide all the information requested. At present, most sites do not require badged visitors or nonresident employees to furnish all the information that would be needed for these files. This issue is recommended for further review by a DOE ad hoc committee. 


\section{DISTRIBUTION}

No. of

Copies

\section{OFFSITE}

35 E. J. Vallario, Group Leader Health Physics Office of Nuclear Safety U.S. Department of Energy Washington, DC 20545

25 J. F. Fitzgerald Office of Nuclear Safety U.S. Department of Energy Washington, DC 20545

J. Maher, Director Office of Nuclear Safety U.S. Department of Energy Washington, DC 20545

L. J. Deal, Director Division of Radiological Controls Office of Nuclear Safety U.S. Department of Energy Washington, DC 20545

\section{DOE Technical Information Center}

D. E. Patterson, Director Operational Safety Division U.S. Department of Energy Washington, DC 20545

D. M. Ross, Chief Health Protection Branch Operational Safety Division U.S. Department of Energy Washington, DC 20545
No. of

Copies

E. N. Patigalia

Performance Measurements Group

Policy, Measurements and

Institutional Standards Branch Operational Safety Division U.S. Department of Energy Washington, DC 20545

C. A. Wood

Performance Measurements Group

Policy, Measurements and Institutional Standards Branch Operational Safety Division U.S. Department of Energy Washington, DC 20545

C. L. Soden

U.S. Department of Energy Albuquerque Operations Office P.0. Box 5400

Albuquerque, NM 87115

P. M. Ramey Operationa 1 Safety Division U.S. Department of Energy Albuquerque Operations Office P.0. Box 5400

A1buquerque, NM 87115

P. Neeson

U.S. Department of Energy Chicago Operations Office 9800 S. Cass Avenue Argonne, IL 60439 
No. of

Copies

R. M. Moser

Safety Division

U.S. Department of Energy

Chicago Operations Office

9800 S. Cass Avenue

Argonne, IL 60439

J. Osloond

U.S. Department of Energy

Idaho Operations Office

550 2nd St.

Idaho Falls, ID 83401

R. J. Beers

Operational Safety Division

U.S. Department of Energy

Idaho Operations office

550 2nd St.

Idaho Falls, ID 83401

M. Marel1 i

U.S. Department of Energy

Nevada Operations Office

P.0. Box 14100

Las Vegas, NV 98114

B. W. Church

Office of Environment and Safety

U.S. Department of Energy

Nevada Operations Office

P.0. Box 14100

Las Vegas, NV 98114

M. Lepper

U.S. Department of Energy Oak Ridge Operations Office

P.0. Box E

Oak Ridge, TN 37830

W. H. Travis

Safety Division

U.S. Department of Energy

Oak Ridge Operations Office

P.0. Box E

Oak Ridge, TN 37830
No. of

Copies

C. Taylor

U.S. Department of Energy

San Francisco Operations Office 1333 Broadway, Wells Fargo Bldg. Oakland, CA 94612

J. Davis

Environment and Safety Division

U.S. Department of Energy

San Francisco Operations Office

1333 Broadway, Wells Fargo Bldg.

0akland, CA 94612

W. Dillow

U.S. Department of Energy

Savannah River Operations Office

P. 0. Box A

Aiken, SC 29801

W. A. Reese, Director

Safety and Environmental Division

U.S. Department of Energy

Savannah River Operations Office

P. 0. Box A

Aiken, SC 29801

R. E. Casey

Brookhaven National Laboratory

Upton, NY 11973

B. Rich

EG\&G Idaho, Inc.

P.0. Box 1625

Idaho Falls, ID 83415

J. L. Clark

System Safety Development Center

EG\&G Idaho Inc.

P.0. Box 1625

Idaho Falls, ID 83415

J. R. Fielding

System Safety Development Center

EG\&G Idaho Inc.

P.0. Box 1625

Idaho Falls, ID 83415 
W. H. Millet

System Safety Development Center

EG\&G Idaho Inc.

P.0. Box 1625

Idaho Falls, ID 83415

J. Elliott

Lawrence Livermore National Laboratory

7000 East Avenue

Livermore, CA 94550

P. Humphrey

MS F692

Los Alamos National Laboratory

Los Alamos, NM 87545

J. Lawrence

MS P229

Los Alamos National Laboratory

Los Alamos, NM 87545

\section{A. Maluish}

Research Services, Inc.

65 Bralan Ct.

Gaithersburg, MD 20877

D. W. Murphy

Reynolds Electrical and Engineering Company

3084 S. Highland

Las Vegas, NV 89114
R. E. Yoder

Rockwell International

P. 0. Box 464

Golden, CO 80401

J. D. McLendon

Union Carbide

Y-12 Plant

Oak Ridge, TN 37830

ONSITE

3 DOE Richland Operations Office

P. L. Clark/H. E. Ransom

J. L. Rhoades

G. R. Yesberger

52 Pacific Northwest Laboratory

J. L. Baer

V. L. Berndt

T. H. Essig

L. G. Faust

J. J. Fix

K. R. Heid

H. W. Hunt

J. J. Jech

B. L. Murphy (25)

J. M. Selby (10)

R. J. Traub (2)

Publishing Coordination (2)

Technical Information (5) 
